\title{
Investor Protection, Optimal Incentives, and Economic Growth*
}

\author{
Rui Castro ${ }^{\dagger} \quad$ Gian Luca Clementi ${ }^{\ddagger} \quad$ Glenn MacDonald ${ }^{\S}$
}

This version: October 28, 2003

\begin{abstract}
Recent empirical evidence has suggested a positive association between various measures of investor protection and financial markets' development, and between financial markets' development and economic growth. We introduce investor protection in a simple extension of the two-period overlapping generations model of capital accumulation and study how it affects economic growth. Investor protection is positively related to risk-sharing. As is standard in models of investment with risk-averse agents, better protection (better risk sharing) results in a larger demand for capital. This is the demand effect. A second effect, which we call the supply effect, follows from general equilibrium restrictions. For a given aggregate capital stock, better protection (i.e. a higher demand schedule) implies a higher interest rate. The aggregate resource constraint then implies lower income for the entrepreneurs (the younger cohort). As a result, current savings and the supply of capital in the following period decrease. It turns out that the strength of the supply effect is greater, the tighter the restrictions on capital flows. Therefore our model predicts that the positive effect of investor protection on growth is stronger for countries with lower restrictions. We find that the data provides some support for this prediction.
\end{abstract}

Key words. Optimal Financing Contracts, Investor Protection, Growth, Overlapping Generations, Capital Mobility.

JEL Codes: D52, D82, D91, D92, E44.

${ }^{*}$ We are grateful to Neil Wallace, Andy Abel, Cevdet Aydemir, Dave Backus, Robert Chirinko, Scott Freeman, Sílvia Gonçalves, Richard Green, Charlie Himmelberg, Narayana Kocherlakota, Hanno Lustig, Mark Manuszak, Martin Schneider, and Bruce Smith, as well seminar attendants at British Columbia, Carnegie Mellon, Duke, Iowa, NC State, NYU, Philadelphia Fed, Richmond Fed, Rochester, SUNY at Albany, University College London, UT Austin, Toronto, Wharton, Colloque CIREQ at the Université de Montréal, the 2002 SED Meeting in New York City, the 2002 NBER Summer Institute, the 2002 SITE Workshop, the 2003 ES Winter Meeting (Washington), the 2003 WFA meeting (Cabo San Lucas), the 2003 ES Australasian meeting (Sydney), and the 2003 EEA meeting (Stockholm) for their comments and suggestions. All remaining errors are our own responsibility. We thanks Dennis Quinn for providing us with his data set. Castro acknowledges financial support from the SSHRC (Canada) and the FCAR (Québec). Clementi thanks CIREQ and the Department of Economics at the Université de Montréal for their generous hospitality at various stages of this project.

${ }^{\dagger}$ Department of Economics and CIREQ, Université de Montréal. Email: rui.castro@umontreal.ca. Web: http://www.fas.umontreal.ca/sceco/castroru

${ }^{\ddagger}$ Department of Economics, Stern School of Business, New York University. Email: gclement@stern.nyu.edu. Web: http://pages.stern.nyu.edu/ gclement

${ }^{\S}$ Olin School of Business, Washington University in St.Louis. Email: macdonald@wustl.edu. Web: http://www.olin.wustl.edu/faculty/macdonald.html 


\section{Introduction}

Recent work beginning with La Porta et al. (1998) has documented considerable cross-country differences in many indicators of investor protection. These indicators measure the extent to which commercial law and its enforcement protect investors from expropriation by company insiders. Importantly, La Porta et al. (1997) found that countries with poorer investor protection have smaller and narrower financial markets: relative to the size of the economy, individuals in these countries trade less often in financial markets; the value of publicly traded securities is lower; and the overall number of market participants is also lower. Work by King and Levine (1993a,b) and Levine and Zervos (1998) has found that well-functioning financial markets are positively associated with economic growth. Using micro data, Rajan and Zingales (1998) and Demirgüç and Maksimovic (1998) documented the same type of association. Together, these results suggest a link between investor protection and growth.

In this paper we investigate the effects of investor protection on growth in a simple extension of the overlapping generations model of capital accumulation due to Diamond (1965). In our setup, each young individual has access to a decreasing returns to scale production technology. In contrast to Diamond, the outcome of the production process is stochastic, i.i.d. across technologies, and known only to the technology's owner. Lacking an initial endowment, and needing resources to use their technology, young individuals, who we refer to as entrepreneurs, borrow capital from the old through financial intermediaries. These intermediaries transfer resources from the old to the young by borrowing from the old at the equilibrium rental rate and lending to the young using optimal lending contracts with terms contingent on all public information. In common with much of the literature on optimal contracts with hidden information, we model the interaction between intermediaries and entrepreneurs as a message game.

We assume that entrepreneurs who misreport their outcomes and hide resources face a deadweight loss. A fraction of the resources hidden from investors gets wasted. If hiding is costless, we say that there is no investor protection. If hiding is so difficult that all hidden resources are lost, investor protection is perfect. Our hiding cost resembles the falsification cost considered by Lacker and Weinberg (1989) and is intended to capture all institutional features that limit the ability of insiders to expropriate outside investors. 
We first show that the degree of risk sharing implied by the optimal contract is monotone in the level of investor protection. The better the protection, i.e. the larger the cost of hiding resources, the lower the risk borne by borrowers. Therefore, better investor protection leads to better risk sharing. Our main result is that the relation between investor protection and growth depends on two opposing effects. The first effect, which we call the demand effect, supports a positive association between investor protection and growth. An improvement in investor protection leads to better risk sharing. As in any partial equilibrium model of investment with riskaverse entrepreneurs, better risk sharing implies a larger demand for capital at any given interest rate. The second effect, which we call the supply effect, is a general equilibrium effect that always works in the direction of a negative association between investor protection and growth. For a given aggregate capital stock, better investor protection (i.e. a higher demand schedule) implies a higher interest rate, which, given the total resources available, translates into lower income for entrepreneurs. In other words, an improvement in investor protection prompts a redistribution away from entrepreneurs (the young generation) towards lenders (the old generation). As a result, current savings and the supply of capital in the following period decrease.

We find that the strength of the supply effect, and therefore the sign of the net effect, depends on international capital mobility. In an economy with no cross-border capital flows, the impact of the supply effect is greatest. As a result, better investor protection can lead to lower growth rates and lower steady state values for both capital and output. At the other extreme, in a small economy without restrictions on capital flows, the interest rate is fixed by world capital markets, so that the supply effect disappears, and more investor protection implies higher growth rates and higher steady state values for both capital and output. Presumably the extent of capital mobility for most national economies is somewhere between these two extreme cases. Thus, both the demand and the supply effects will typically be at work, with the strength of the supply effect increasing with the extent to which the government hinders capital flows. It follows that the positive effect of investor protection on growth should be larger for countries that impose lower restrictions on capital flows.

Do cross-country data provide any support for our predictions? We answer this question by applying a variety of methodologies. First, we document the positive association between the indicators of investor protection introduced by La Porta et al. (1998), and two indirect measures of risk sharing. Then, we investigate whether the relationship between investor protection and growth depends on the extent to which 
capital flows are restricted. Using standard techniques from the empirical growth literature, we show that the (positive) impact of investor protection on growth is much larger for open economies than for closed ones. Finally, we consider in detail the development experience of a particular country pair: South Korea and India. We ask why, in the post-WWII period, what looked like similar growth-promoting policies resulted in a much higher saving rate and growth rate in Korea than in India. We argue that differences in institutions might have mattered. According to La Porta et al. (1998), India has better investor protection than Korea. Since both countries have severely restricted capital flows, the outcome just described is what our model suggests would be observed.

The theoretical literature on the effects of investor protection is small but growing rapidly. In particular, our work is related to recent contributions by Himmelberg et al. (2002), Shleifer and Wolfenzon (2002), Almeida and Wolfenzon (2002), and Himmelberg and Quadrini (2002). Himmelberg et. al. consider the investment decision of a risk-averse entrepreneur who raises funds from outside investors. Investor protection is modelled as the cost the insider incurs when diverting resources from his financiers. Their model predicts that poorer investor protection is associated with larger ownership concentration and less risk sharing, and therefore smaller firm size. ${ }^{1}$ Shleifer and Wolfenzon embed Himmelberg et. al.'s agency model in a static equilibrium setup. They show how investor protection affects the size of the equity market and the number of public firms. Almeida and Wolfenzon study the allocation of capital in a 2-period equilibrium model, under the assumption that imperfect enforcement of contracts limits the ability of entrepreneurs to commit to repay their financiers. Finally, Himmelberg and Quadrini study the optimal dynamic financing contract between a risk-averse entrepreneur and a risk-neutral investor under the assumption that the latter might not observe the entrepreneur's revenues. They show that ownership concentration is lower when investors are more likely to observe the revenues (i.e. when investor protection is better).

Our paper can also be seen as part of a large theoretical literature analyzing the relation between capital accumulation and imperfections in financial markets. Papers that investigate the effects of imperfect risk sharing on savings in general equilibrium are particularly related to ours, e.g., Aiyagari (1994) and Devereux and Smith (1994).

\footnotetext{
${ }^{1}$ Himmelberg et al. (2002) estimate the size of the risk-premium dictated by ownership concentration and use their model along with data on inside ownership to determine a measure of its effect on firm size.
} 
Aiyagari studies the effects of market incompleteness on the steady state capital stock in a version of the standard growth model. In his model, precautionary savings are responsible for the positive effect of imperfect risk sharing on capital accumulation. Devereux and Smith study a multi-country model in which each country faces income risk, but there is no uncertainty at the worldwide level. Growth rates in all countries turn out to be lower when financial markets are integrated. Again, this happens because the ability to trade lowers the importance of the precautionary motive. Our framework differs from Aiyagari's and Devereux and Smith's along several dimensions. First, in their models individuals borrow for the purpose of consumption smoothing, while in ours they raise funds in order to finance investment. Second, in our scenario there is no precautionary motive, since second-period income is known to the agents when they make their saving decision. Finally, in our model the degree of market incompleteness is endogenous.

As it is the case here, in Marcet and Marimon (1992) and Khan and Ravikumar (2001) the assumption of asymmetric information is responsible for suboptimal risk sharing. However, their implications for growth are different. In Marcet and Marimon (1992) imperfect risk sharing has no effect on capital accumulation. Khan and Ravikumar (2001) find that the economy with private information (and partial insurance) displays lower growth rates of capital and output than the economy with symmetric information (and full insurance). In Section 3.2 we discuss at length the fundamental differences between our framework and theirs.

Finally, our work is also related to the seminal theoretical studies of the relationship between financial market development and growth, such as Greenwood and Jovanovic (1990) and Bencivenga and Smith (1991).

The remainder of the paper is organized as follows. The model is introduced in Section 2. Section 3 characterizes the competitive equilibrium allocation in a closed economy, and identifies the demand and supply effects. In Section 4 we explore the small open economy case. In Section 5 we derive the empirical implication for the relation between investor protection, capital mobility, and growth and we conduct the data analysis. Section 6 concludes. 


\section{Model}

We consider a simple extension of the standard two-period Overlapping Generations Model. $^{2}$ The population is constant and the measure of each cohort is normalized to one. Individuals are risk-averse. Preferences are time-separable and the period utility, denoted by $u\left(c_{t}\right)$, displays constant relative risk aversion. ${ }^{3}$ Let $\sigma$ denote the coefficient of relative risk aversion. Agents discount second-period utility at the rate $\beta ; \beta \in(0,1)$.

Young individuals, the entrepreneurs, are endowed with investment opportunities described by the technology $F\left(z_{t}, k_{t}\right)=z_{t} f\left(k_{t}\right)$, where $k$ denotes physical capital. We assume that $f$ is $C^{2}$ and satisfies $f(0)=0, f^{\prime}>0, f^{\prime \prime}<0, \lim _{k \rightarrow 0} f^{\prime}(k)=\infty$, and $\lim _{k \rightarrow \infty} f^{\prime}(k)=0$. Capital depreciates at the constant rate $\delta \in(0,1)$. The random variable $z_{t}$ determines the quality of the investment project. We assume that for every $t, z_{t} \in\left\{z_{l}, z_{h}\right\}$, where $z_{h}>z_{l}$ and $\operatorname{pr}\left\{z_{t}=z_{h}\right\}=\rho ; \rho \in(0,1) .{ }^{4}$ Old individuals do not work, and consume from assets accumulated when young.

Since entrepreneurs have no endowment, they can undertake their projects only if the old generation finances them. We assume financial intermediaries that borrow capital from the old cohort at the equilibrium rental rate, and lend to entrepreneurs via Constrained-Pareto optimal one-period contracts. ${ }^{5}$ The intermediation sector is perfectly competitive and has free-entry.

The realization of the random variable $z_{t}$ is private information for the entrepreneurs, who have the option of hiding some of their cash-flows from their financiers. Hiding, however, is costly. For every unit of cash-flow hidden, an entrepreneur ends up with only the fraction $\xi \in[0,1]$. The balance is lost in the hiding process. ${ }^{6}$ The parameter $\xi$ is our measure of investor protection - the larger is $\xi$, the lower the protection. The two extreme values identify the cases of complete absence of protection $(\xi=1)$ and perfect protection $(\xi=0)$.

\footnotetext{
${ }^{2}$ Our setup is similar to the one used by Lacker et al. (1990) to study the asset pricing implications of asymmetric information. As it will become clear, none of our results hinges upon the assumption of two-period lives.

${ }^{3}$ We restrict our attention to the CRRA family, because utility functions in this class display non-increasing absolute risk-aversion and imply indirect utility functions that are log-separable in the interest rate. Both features are needed to establish our main results.

${ }^{4}$ It is straightforward to modify our setup to allow for balanced growth, provided that the technology is consistent with it (e.g. with Cobb-Douglas). It suffices to assume that $z_{i, t+1} / z_{i, t}=\gamma>1$ for $i=h, l$. All of our results would hold for the modified model, once variables are detrended.

${ }^{5}$ In Appendix A we discuss why do we focus on one-period contracts.

${ }^{6}$ All of our results follow even when a portion, or the totality of this balance accrues to the intermediaries. The only caveat is that in such case it is necessary to work with a continuum of outcomes. Otherwise, any hiding would be detected by the lender. See Appendix B for details.
} 


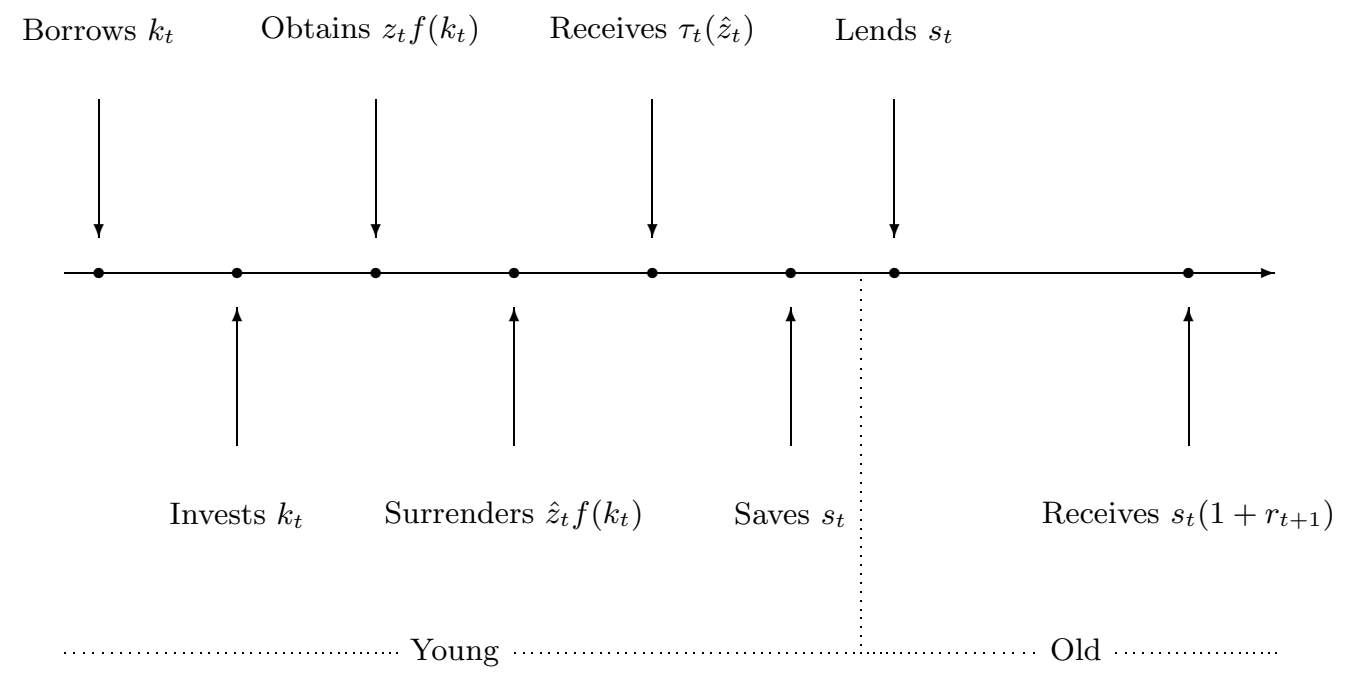

Figure 1: Timing.

Figure 1 displays the timing assumed in the model. At the outset, an entrepreneur borrows capital, $k_{t}$, from an intermediary, then invests and produces output equal to $z_{t} f\left(k_{t}\right)$. Next, he makes a claim about the quality of his project $\hat{z}_{t} \in\left\{z_{h}, z_{l}\right\}$, gives the intermediary output consistent with this claim, i.e. $\hat{z}_{t} f\left(k_{t}\right)$, and receives a contingent transfer $\tau_{t}\left(\hat{z}_{t}\right){ }^{7}$ Therefore a financing contract consists of a capital advance, $k_{t}$, and contingent transfers $\tau_{h t}$ and $\tau_{l t}$.

At the end of the first period, entrepreneurs end up with income we denote by $m_{t}$. If the project is of low quality, necessarily $m_{t}=\tau_{l t}$. Having no endowment, an agent is unable to misreport in the low state, since that would entail surrendering a level of output $z_{h} f\left(k_{t}\right)$. If the project is of high quality, truthful reporting yields $m_{t}=\tau_{h t}$, and concealing yields $m_{t}=\tau_{l t}+\xi \Delta f\left(k_{t}\right)$, where $\Delta \equiv z_{h}-z_{l}$. By misreporting, the entrepreneur receives the transfer intended for low quality projects, $\tau_{l t}$, plus the fraction $\xi$ of the hidden output $\Delta f\left(k_{t}\right)$. At the end of the first stage of their lives, agents consume part of their income and save the rest. At the beginning of the second stage, they lend their savings to intermediaries at the market rate. Intermediaries channel those funds to the new cohort of young people. At the end of their lives, agents receive and consume principal and interest.

\footnotetext{
${ }^{7}$ In Appendix B we show that under our assumptions the Constrained-Pareto optimal contract always requires the output surrendered to be consistent with the report. In turn, this implies no hiding along the equilibrium path.
} 


\section{Competitive equilibrium}

We start by considering an entrepreneur's consumption-saving decision. Let $v\left(m_{t}, r_{t+1}\right)$ denote the indirect utility of an agent born at time $t$, conditional on having received an income $m_{t}$ and on facing an interest rate $r_{t+1}$. Then,

$$
v\left(m_{t}, r_{t+1}\right) \equiv u\left[m_{t}-s\left(m_{t}, r_{t+1}\right)\right]+\beta u\left[\left(1+r_{t+1}\right) s\left(m_{t}, r_{t+1}\right)\right],
$$

where the optimal saving function $s\left(m_{t}, r_{t+1}\right)$ is

$$
s\left(m_{t}, r_{t+1}\right) \equiv \arg \max _{s}\left\{u\left(m_{t}-s\right)+\beta u\left[\left(1+r_{t+1}\right) s\right]\right\} .
$$

An optimal contract is a triple $\left(k_{t}, \tau_{h t}, \tau_{l t}\right)$ that solves the optimization problem:

$$
\max _{k_{t}, \tau_{h t}, \tau_{l t}} \rho v\left(\tau_{h t}, r_{t+1}\right)+(1-\rho) v\left(\tau_{l t}, r_{t+1}\right)
$$

subject to incentive compatibility for entrepreneurs whose projects are high quality, i.e.,

$$
v\left(\tau_{h t}, r_{t+1}\right) \geq v\left[\tau_{l t}+\xi \Delta f\left(k_{t}\right), r_{t+1}\right],
$$

and the zero-profit condition for intermediaries:

$$
\bar{\tau}_{t} \equiv \rho \tau_{h t}+(1-\rho) \tau_{l t}=\bar{z} f\left(k_{t}\right)-\left(r_{t}+\delta\right) k_{t},
$$

where $\bar{z} \equiv \rho z_{h}+(1-\rho) z_{l}$. We now define a competitive equilibrium. ${ }^{8}$

Definition 1 Given an initial capital stock $k_{0}>0$, a competitive equilibrium is a consumption level of the initial old $c_{0}^{o}$, contingent consumption allocations for young and old individuals, $\left\{c_{h t}^{y}, c_{l t}^{y}\right\}_{t=0}^{\infty}$ and $\left\{c_{h t}^{o}, c_{l t}^{o}\right\}_{t=1}^{\infty}$, and sequences of contracts, $\left\{k_{t}, \tau_{h t}, \tau_{l t}\right\}_{t=0}^{\infty}$, and interest rates, $\left\{r_{t}\right\}_{t=0}^{\infty}$, such that

1. consumers optimize, i.e. $c_{0}^{o}=k_{0}\left(1+r_{0}\right)$, and for $i=h, l$ and $t \geq 0, c_{i t}^{y}=$ $\tau_{i t}-s\left(\tau_{i t}, r_{t+1}\right)$ and $c_{i t+1}^{o}=s\left(\tau_{i t}, r_{t+1}\right)\left(1+r_{t+1}\right)$;

2. contracts are optimal, i.e. for all $t \geq 0$, they solve problem (P1); and

3. the goods market clears at all $t \geq 0$ :

$$
k_{t+1}=\rho s\left(\tau_{h t} ; r_{t+1}\right)+(1-\rho) s\left(\tau_{l t} ; r_{t+1}\right) .
$$

\footnotetext{
${ }^{8}$ Since every generation consists of a measure one of ex-ante identical individuals, the capital assigned to every entrepreneur must equal aggregate capital. For this reason, we use the same notation for the two variables.
} 
In the remainder of this section we characterize the evolution of this economy, and then explore how the nature of financial claims and the paths of variables such as capital and output change in response to variations in the investor protection parameter $\xi$.

\subsection{Benchmark: Perfect investor protection $(\xi=0)$}

For $\xi=0$, our model is isomorphic to Diamond (1965)'s. Thus, for every $t$, given an interest rate $r_{t}$, the demand for capital satisfies the optimality condition

$$
\bar{z} f^{\prime}\left(k_{t}\right)-\delta=r_{t} .
$$

Also, strict concavity of the utility function implies $\tau_{h t}=\tau_{l t}$. Since intermediaries are risk neutral, an optimal contract insures entrepreneurs fully, making intermediaries residual claimants on the projects' cash-flows. From the zero-profit condition, together with (5), transfers are functions of capital only, and are given by

$$
\tau_{t}=\tau\left(k_{t}\right)=\bar{z}\left[f\left(k_{t}\right)-f^{\prime}\left(k_{t}\right) k_{t}\right] .
$$

The gross return on investment for the intermediaries $R_{i t}$ is given by

$$
R_{i t}=\frac{z_{i} f\left(k_{t}\right)-\tau_{t}}{k_{t}} \text { for } i=h, l,
$$

and it follows that

$$
R_{h t}-R_{l t}=\frac{\Delta f\left(k_{t}\right)}{k_{t}} .
$$

The financial claims held by the intermediaries resemble equity claims. Finally, given $k_{0}>0$, the behavior of the economy is completely described by (5), along with the difference equation

$$
k_{t+1}=s\left[\tau\left(k_{t}\right) ; r_{t+1}\right] .
$$

For $\xi=0$, our economy evolves exactly as a standard OLG model with constant productivity $\bar{z}$, competitive capital and labor markets, and inelastic labor supply; the wage is equal to $\tau_{t}$.

\subsection{Imperfect investor protection $(\xi \in(0,1])$}

In this subsection we show that when $\xi>0$, the effect of investor protection on capital accumulation can be decomposed into a (positive) demand effect and a (negative) general equilibrium effect on supply. While the net effect ultimately depends on the utility specification, it turns out that for a large subset of the parameter space better 
investor protection leads to less investment and less accumulation. The intuition is as follows. Lower $\xi$ (better investor protection) implies better risk sharing. This implies that entrepreneurs will demand more capital for a given interest rate. This is the demand effect. For given capital, however, lower risk will demand a lower expected return. That is, the average level of transfers from intermediaries to entrepreneurs will be lower. This implies that in average entrepreneurs will earn less and save less, so that the capital supply curve will also be lower. This is the supply effect. In the remainder of this section, we characterize the demand effect and then we show how it interacts with the supply effect.

First, observe that for any $r_{t+1}, v\left(\tau_{t}, r_{t+1}\right)$ is strictly increasing and strictly concave in $\tau_{t}$. By strict concavity, (2) must bind in the solution. Then, by strict monotonicity, it follows that $\tau_{h t}=\tau_{l t}+\xi \Delta f\left(k_{t}\right)$ for any $t$. By the zero-profit condition (3), transfers are given by

$$
\tau_{l t}=\tau_{l}\left(k_{t}, r_{t}\right)=(\bar{z}-\rho \xi \Delta) f\left(k_{t}\right)-\left(r_{t}+\delta\right) k_{t}
$$

and

$$
\tau_{h t}=\tau_{h}\left(k_{t}, r_{t}\right)=(\bar{z}+(1-\rho) \xi \Delta) f\left(k_{t}\right)-\left(r_{t}+\delta\right) k_{t} .
$$

Substituting for $\tau_{l t}$ and $\tau_{h t}$ in (6) yields

$$
R_{h t}-R_{l t}=\frac{(1-\xi) \Delta f\left(k_{t}\right)}{k_{t}} .
$$

Risk-sharing is imperfect. Since $\left(R_{h t}-R_{l t}\right) k_{t}<\Delta f\left(k_{t}\right)$, entrepreneurs bear part of the risk. Also, this part is increasing in $\xi$. In the extreme, when $\xi=1$, the contract provides no risk sharing at all, and the claim held by the intermediary amounts to a standard debt contract. There is some empirical evidence that countries with better investor protection also provide entrepreneurs with better opportunities for risk sharing. We discuss this evidence in Section 5.1.

We now show that the aggregate demand for capital is decreasing in both $r_{t}$ and $\xi$. Using the incentive compatibility condition, and letting $y_{t} \equiv f\left(k_{t}\right)$, problem $(\mathrm{P} 1)$ can be restated as

$$
\max _{\bar{\tau}_{t}, y_{t}} V\left(\bar{\tau}_{t}, y_{t}\right) \equiv \rho v\left[\bar{\tau}_{t}+(1-\rho) \Delta \xi y_{t}, r_{t+1}\right]+(1-\rho) v\left[\bar{\tau}_{t}-\rho \Delta \xi y_{t}, r_{t+1}\right],
$$

subject to

$$
\bar{\tau}_{t}=\bar{z} y_{t}-\left(r_{t}+\delta\right) f^{-1}\left(y_{t}\right) .
$$

$V\left(\bar{\tau}_{t}, y_{t}\right)$ implies a collection of level sets. The necessary conditions associated with problem (P1) can be expressed in terms of tangency between these level sets and (BC). 
For given $r_{t}$ and $r_{t+1}$, the optimal pair $\left(\bar{\tau}_{t}, y_{t}\right)$ must solve the system of equations given by the budget constraint $(\mathrm{BC})$ and the condition

$$
\left.\frac{\partial \bar{\tau}_{t}}{\partial y_{t}}\right|_{B C}=\left.\frac{\partial \bar{\tau}_{t}}{\partial y_{t}}\right|_{V} .
$$

Using the envelope theorem:

$$
\begin{aligned}
& \left.\frac{\partial \bar{\tau}_{t}}{\partial y_{t}}\right|_{B C}=\bar{z}-\left(r_{t}+\delta\right) \frac{d f^{-1}\left(y_{t}\right)}{d y_{t}} \\
& \left.\frac{\partial \bar{\tau}_{t}}{\partial y_{t}}\right|_{V}=-\rho(1-\rho) \xi \Delta \frac{u^{\prime}\left(c_{h t}\right)-u^{\prime}\left(c_{l t}\right)}{\rho u^{\prime}\left(c_{h t}\right)+(1-\rho) u^{\prime}\left(c_{l t}\right)}>0 .
\end{aligned}
$$

Since $f$ and $u$ are strictly concave functions, the level sets for $V\left(\bar{\tau}_{t}, y_{t}\right)$ are strictly convex and the budget constraint is strictly concave. It follows that the optimal pair $\left(\bar{\tau}_{t}, y_{t}\right)$ is unique. Furthermore, since the budget constraint is steeper at $y_{t}=0$, $\bar{\tau}_{t}, y_{t}>0$. Since $f$ is strictly increasing, the optimal $y_{t}$ uniquely determines an optimal $k_{t}=f^{-1}\left(y_{t}\right)$. The consumption allocations are then given by

$$
c_{i t}=\tau_{i}\left(k_{t}\right)-s\left(\tau_{i}\left(k_{t}\right) ; r_{t+1}\right) \quad \text { for } i=h, l .
$$

Under our assumptions on preferences, it follows that

$$
c_{i t}=\left[1-\kappa\left(r_{t+1}\right)\right] \tau_{i t} \text { for } i=h, l,
$$

where

$$
\kappa\left(r_{t+1}\right)=\frac{1}{1+\beta^{-\frac{1}{\sigma}}\left(1+r_{t+1}\right)^{\frac{\sigma-1}{\sigma}}} .
$$

Finally, since the indirect utility function is $\log$-separable in $r_{t+1}$, we can rewrite the slope of the indifference curves as

$$
\left.\frac{\partial \bar{\tau}_{t}}{\partial y_{t}}\right|_{V}=-\rho(1-\rho) \xi \Delta \frac{u^{\prime}\left(\tau_{h t}\right)-u^{\prime}\left(\tau_{l t}\right)}{\rho u^{\prime}\left(\tau_{h t}\right)+(1-\rho) u^{\prime}\left(\tau_{l t}\right)}>0 .
$$

In turn, this implies that the optimal pair $\left(k_{t}, \bar{\tau}_{t}\right)$ (and the aggregate demand for capital) does not depend on $r_{t+1}$.

For given $k_{0}>0$, the economy's evolution is completely characterized by conditions (9) and (BC), which define the demand for capital $k_{t}=D\left(r_{t} ; \xi\right)$, together with (4), which defines the supply of capital $k_{t+1}=S\left(k_{t}, r_{t}, r_{t+1}\right)$.

Proposition 1 The function $D\left(r_{t}, \xi\right)$ is strictly decreasing in both $r_{t}$ and $\xi$. 


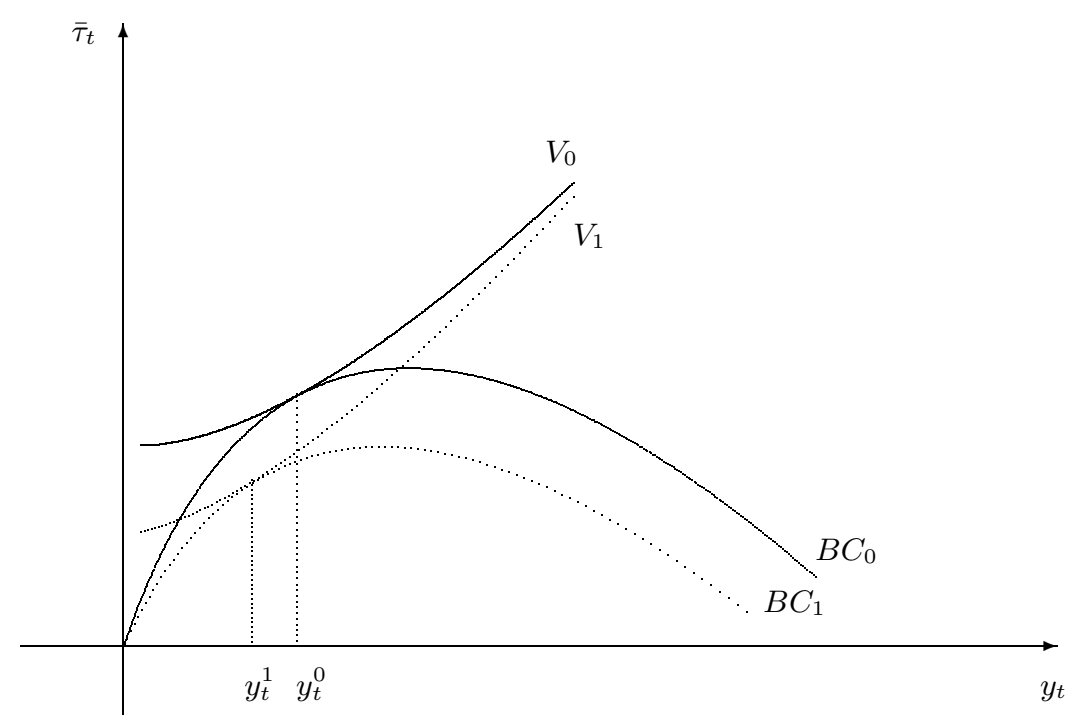

Figure 2: Effect of an increase in $r_{t}$.

Proof. 1. $D\left(r_{t} ; \xi\right)$ is decreasing in $r_{t}$. Refer to Figure 2. Start with an optimal $k_{t}^{0}$. This implies $y_{t}^{0}=f\left(k_{t}^{0}\right)$ and a level of the interest rate $r_{t}^{0}=D^{-1}\left(k_{t}^{0}, \xi\right)$. Now consider any $r_{t}^{1}>r_{t}^{0}$. Since $\left.\frac{\partial \bar{\tau}_{t}}{\partial r_{t}}\right|_{B C}=-k_{t}<0$, the budget constraint shifts from $B C_{0}$ to $B C_{1}$. To show that the optimal capital advance associated with the higher interest rate is $k_{t}^{1}<k_{t}^{0}$, it is enough to show that $\frac{\partial}{\partial \bar{\tau}_{t}}\left(\left.\frac{\partial \bar{\tau}_{t}}{\partial y_{t}}\right|_{V}\right) \leq 0$. Simple calculations reveal that $\frac{\partial}{\partial \bar{\tau}_{t}}\left(\left.\frac{\partial \bar{\tau}_{t}}{\partial y_{t}}\right|_{V}\right)=-\frac{\rho(1-\rho) \xi \Delta u^{\prime}\left(\tau_{h t}\right) u^{\prime}\left(\tau_{l t}\right)}{\left[\rho u^{\prime}\left(\tau_{h t}\right)+(1-\rho) u^{\prime}\left(\tau_{l t}\right)\right]^{2}}\left[R_{A}\left(\tau_{l t}\right)-R_{A}\left(\tau_{h t}\right)\right]$, where $R_{A}\left(\tau_{i t}\right) \equiv-\frac{u^{\prime \prime}\left(\tau_{i t}\right)}{u^{\prime}\left(\tau_{i t}\right)}$ denotes the coefficient of absolute risk-aversion. Therefore, a sufficient condition for $\frac{\partial}{\partial \bar{\tau}_{t}}\left(\left.\frac{\partial \bar{\tau}_{t}}{\partial y_{t}}\right|_{V}\right) \leq 0$ is that the utility function displays non-increasing absolute riskaversion. This condition is satisfied by CRRA preferences.

2. $D\left(r_{t} ; \xi\right)$ is strictly decreasing in $\xi$. Refer to Figure 3. Consider any $\xi=\xi_{0} \in$ $(0,1)$. Let $k_{t}^{0}$ denote the corresponding optimal capital advance, and let $y_{t}^{0}=f\left(k_{t}^{0}\right)$. Now consider any $\xi_{1}>\xi_{0}$. The budget constraint BC is invariant to such modification. On the other hand, some algebra shows that risk aversion implies $\frac{\partial}{\partial \xi}\left(\left.\frac{\partial \bar{\tau}_{t}}{\partial y_{t}}\right|_{V}\right)>0$. For given $r_{t}$, the new optimal capital advance $k_{t}^{1}$ must be strictly lower than $k_{t}^{0}$.

We now turn to comparing the dynamics of two economies differing only in terms of $\xi$. Let $\xi$ and $\hat{\xi}$ be the degrees of investor protection in the two economies, and suppose $\hat{\xi}>\xi$. Start with date $t=0$. Since the capital stock is given, the supply of capital by the old generation is completely inelastic at $k_{0}$. The difference in investor protection is reflected in different demand schedules. The result, illustrated in Figure 4 , is that the interest rate $r_{0}$ is lower in the economy with poorer investor protec- 


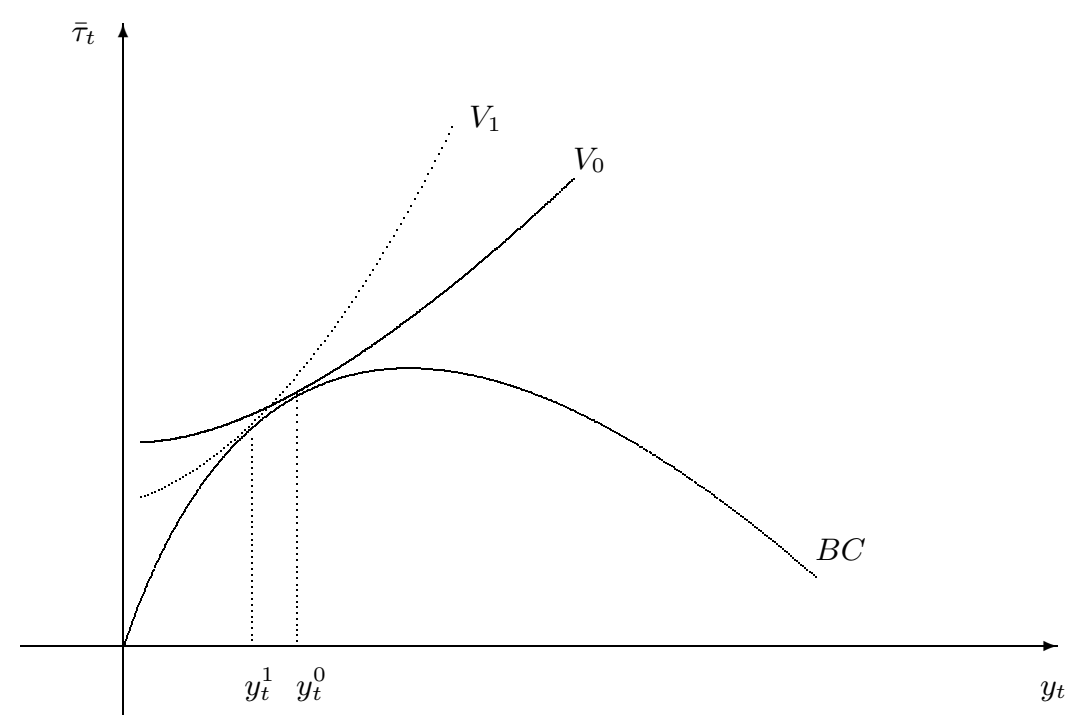

Figure 3: Effect of an increase in $\xi$.

tion, and the expected income of entrepreneurs $\bar{\tau}_{0}$ is higher. The economic intuition is straightforward. Since the number of entrepreneurs is constant, the capital per entrepreneur must be $k_{0}$ in both economies. In the economy with poorer investor protection, the optimal contract allows for less risk sharing. For the young to accept the greater risk, their expected return, $\bar{\tau}_{0}$, must be larger. Finally, the aggregate resource constraint dictates that this can happen only if $r_{0}$ is lower.

From Proposition 1, at any $t$ the demand schedule will be lower the higher the parameter $\xi$. A larger value of $\bar{\tau}_{0}$ implies an outward shift of the supply curve at $t=1$. This results in a higher or lower value of $k_{1}$ depending on the relative slopes of demand and supply, as well as on the magnitudes of their shifts.

If the income effect deriving from an interest rate change dominates the substitution effect in a way that causes the slope of the supply curve to be greater than the slope of the demand curve (in absolute value), then, for all $t \geq 1, k_{t}(\xi)<k_{t}(\hat{\xi})$. This occurs, for example, if the utility function is logarithmic. In such cases, the income and substitution effects exactly offset each other. As a result, savings are a constant proportion of transfers. This implies that at all $t$ the supply of capital is inelastic and given by

$$
k_{t+1}=\frac{\beta}{1+\beta} \bar{\tau}_{t}
$$

Finally, this means that for any pair $(\xi, \hat{\xi})$ with $\hat{\xi}>\xi, \bar{\tau}_{0}(\hat{\xi})>\bar{\tau}_{0}(\xi)$. It will also be the case that $k_{1}(\hat{\xi})>k_{1}(\xi)$ and $r_{1}(\hat{\xi})<r_{1}(\xi)$, and thus $\bar{\tau}_{1}(\hat{\xi})>\bar{\tau}_{1}(\xi)$; refer to 


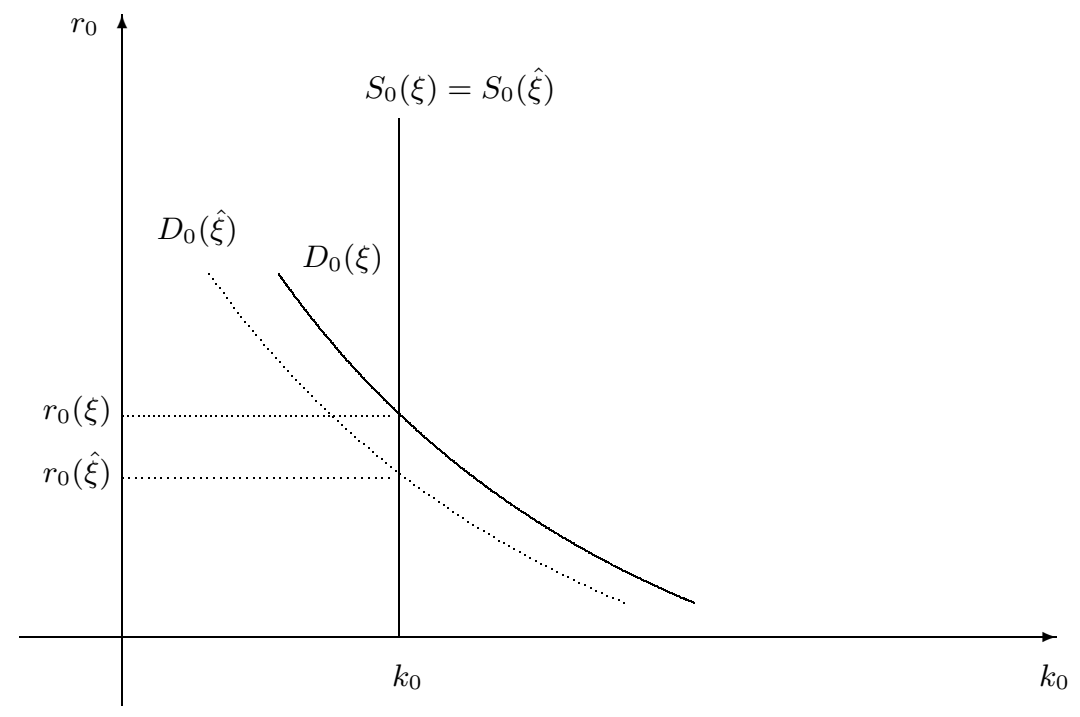

Figure 4: Date $t=0$.

Figure 5. By repeating the same argument at any time $t$, we conclude that capital accumulation is always higher in the economy with poorer investor protection. ${ }^{9}$

\subsection{The Cobb-Douglas production function}

Proposition 2 shows that when the technology is described by a Cobb-Douglas production function, entrepreneurs' income can be expressed in a very convenient form.

Proposition 2 If $f\left(k_{t}\right)=k_{t}^{\alpha}$ with $\alpha \in(0,1)$, then $\tau_{i t}=g_{i} f\left(k_{t}\right)$ for some constants $g_{i}, i=h, l$.

Proof. Since the optimal contract $\left(\bar{\tau}_{t}, k_{t}\right)$ is unique for given $r_{t}$, it suffices to check that $\tau_{i t}=g_{i} f\left(k_{t}\right)$ satisfies the necessary conditions (7), (8) and (9). Therefore, assume that $\tau_{i t}=g_{i} f\left(k_{t}\right)$. Then, (9) implies that

$$
\left(r_{t}+\delta\right) k_{t}=\alpha\left[\bar{z}+\rho(1-\rho) \xi \Delta \frac{u^{\prime}\left(g_{h}\right)-u^{\prime}\left(g_{l}\right)}{\rho u^{\prime}\left(g_{h}\right)+(1-\rho) u^{\prime}\left(g_{l}\right)}\right] k_{t}^{\alpha} .
$$

Substituting this expression in (7) and (8) verifies our conjecture.

The paths for capital stock and interest rate are jointly determined by the contemporaneous equation (10), which determines the demand for capital as a function

\footnotetext{
${ }^{9}$ Notice that, there being no uncertainty in the second stage of people's lives, the precautionary motive for saving is absent in our model. Introducing such motive would only reinforce the supply effect described above, without producing any further insight.
} 


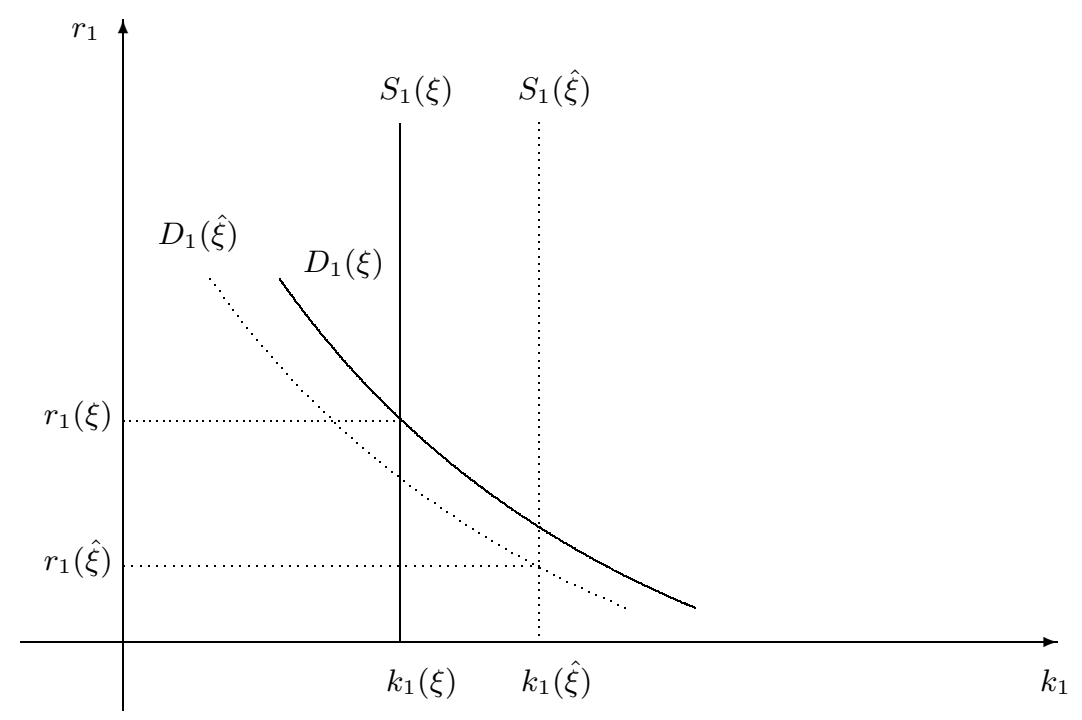

Figure 5: Date $t=1$.

of the interest rate, and by the first-order difference equation

$$
k_{t+1}=\kappa\left(r_{t+1}\right)\left[\rho g_{h}+(1-\rho) g_{l}\right] k_{t}^{\alpha},
$$

which defines the supply of capital.

Assessing the effect of investor protection on capital accumulation with generality is nontrivial. As argued above, the net effect deriving from a change in investor protection depends on the relative slopes of demand and supply. Equations (10) and (11) reveal that both slopes are nonlinear in the same set of parameters. The coefficient of relative risk aversion $\sigma$ plays a particularly important role. Clearly, it affects the magnitude of the demand shift induced by a higher $\xi$. Since $\sigma$ is just the inverse of the intertemporal elasticity of substitution, it also affects the shift of the supply schedule, as well as its elasticity with respect to the interest rate.

As it may be expected, assuming logarithmic utility removes any ambiguity. In this case, $\kappa\left(r_{t+1}\right)=\beta /(1+\beta)$, so the path of capital is uniquely determined by (11). Condition (10) only determines the level of the equilibrium interest rate. Since the term in square brackets in (11) is strictly increasing in $\xi$, we can show that poorer investor protection always implies higher capital accumulation. ${ }^{10}$

It turns out that, even when the coefficient of relative risk aversion is different from 1, our result still holds in most cases. That is, for most parameterizations, a

\footnotetext{
${ }^{10}$ With log preferences the model admits a solution in closed form, i.e., it is possible to express $g_{l}$ and $g_{h}$ as explicit functions of the model's parameters.
} 

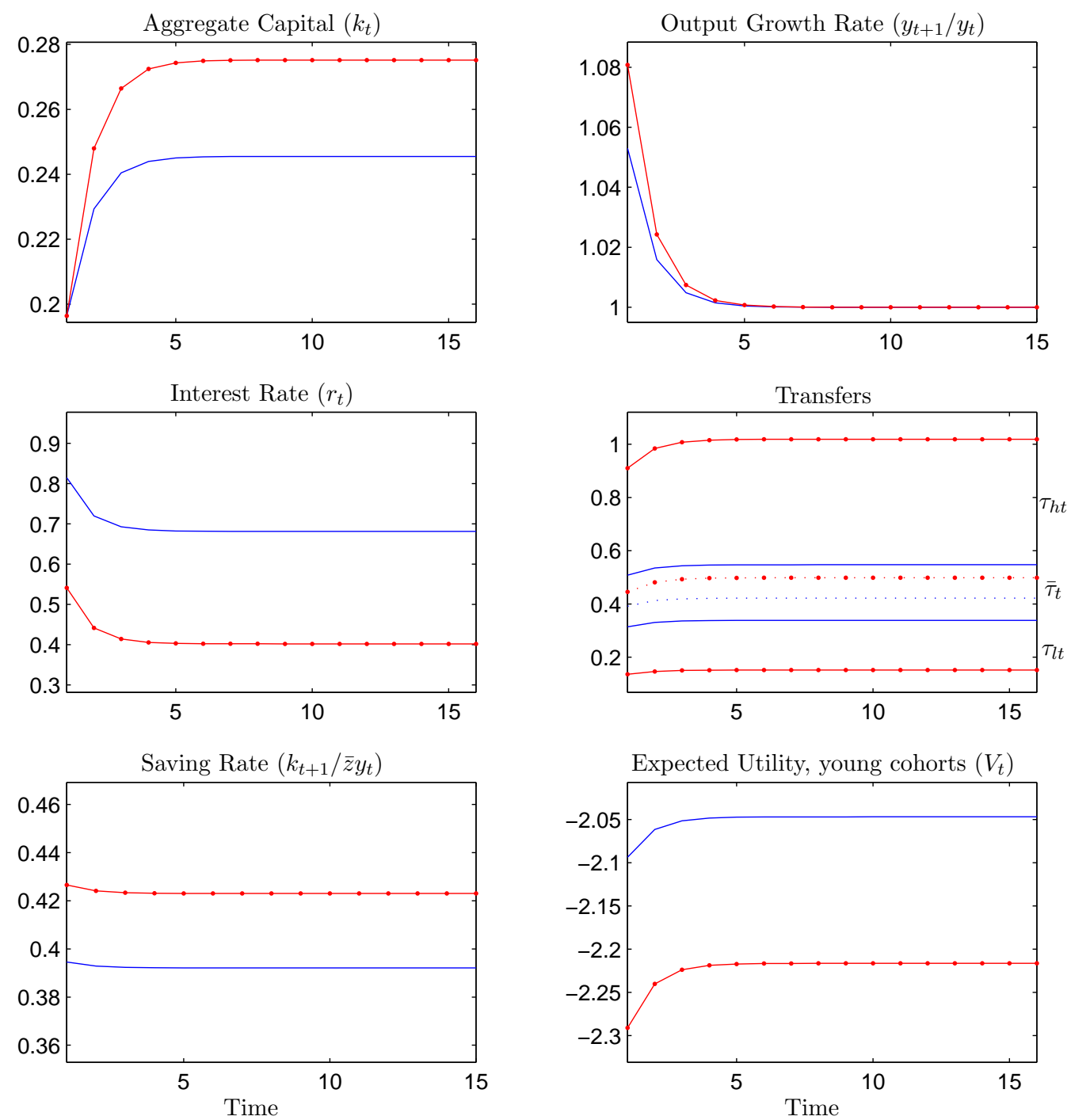

Figure 6: Comparative Dynamics (Dotted line $=$ higher $\xi$ ).

higher value for $\xi$ (poorer investor protection) implies higher levels of capital at all dates. In all such cases, poorer investor protection also implies higher paths for the growth rate of output and the saving rate, and a lower path for the interest rate. Figure 6 shows the typical dynamics of capital, output growth rate, interest rate, entrepreneurial income, saving rate, and welfare, in a scenario with $\sigma \neq 1$. $^{11}$

\footnotetext{
${ }^{11}$ In the panel dedicated to the transfers, the top two paths depict the evolution of $\tau_{h t}$ for two different levels of $\xi$, the middle two paths depict the evolution of $\bar{\tau}_{t}$, and the bottom two the evolution of $\tau_{l t}$. The levels of $\xi$ used to produce the figure are 0.2 and 0.8 , respectively. The other parameter values are $\alpha=1 / 3, \delta=0.15, z_{h}=2, \bar{z}=1, \rho=0.4, \beta=0.99, \sigma=0.6$. There are parameterizations for which a higher $\xi$ leads to lower accumulation. The demand effect tends to dominate when the discount rate $\beta$ is low, so that the propensity to save is also low. For instance, this is the case when $\beta=0.2$, with all remaining parameter values as before.
} 
Notice that the transition paths for capital depicted in Figure 6 could have been generated by economies having the same level of investor protection but different levels of total factor productivity $\bar{z}$. However, according to our model, differences in TFP have very different implications for the behavior of the real interest rate. Contrary to what is implied by a lower level of investor protection, a higher level of TFP yields a uniformly higher path for the interest rate. ${ }^{12}$

In the example in Figure 6, the welfare of all generations is larger when investor protection is better. But this result is not general. At date $t=0$, better investor protection always yields a higher interest rate, so that the old are better off. The welfare of the remaining generations can be increased or decreased by better investor protection, depending on the net effect of three factors, of which two are positive and one is negative. A lower $\xi$ is beneficial because it is associated with better risk sharing. But it also induces an increase in the rental rate at all dates, which lowers every generation's income in the first period (since higher rates mean lower average transfers) and raises it in the second. The net effect is negative for high enough values of the parameter $\alpha{ }^{13}$

\subsection{Interpretation of the results}

The result we have just described, i.e. that for closed economies poorer investor protection is generally associated with higher growth, is due to the fact that lowering the level of protection induces a transfer of resources away from the old and towards the young. As argued above, lowering the level of protection has an adverse impact on the risk-sharing possibilities of entrepreneurs. This implies that for given project size, the entrepreneurs themselves will require a higher expected return. The intergenerational redistribution reflects the extent to which such shift in the demand of capital leads to higher entrepreneurial income. In fact, in general equilibrium, for the young generation to receive more, the old must suffer an income loss. Finally, the positive impact on savings follows from the fact that young individuals have a higher propensity to save. ${ }^{14}$

\footnotetext{
${ }^{12}$ In our model, the real interest rate reflects not only the marginal productivity of capital, but also the degree of risk-sharing in the economy. Equation (10) implies that $r_{t}$ equals the marginal product, $\alpha \bar{z} k_{t}^{\alpha-1}$, plus a negative term which depends on the level of investor protection. Entrepreneurs must be compensated for the risk induced by poor protection. This entails a lower real interest rate.

${ }^{13} \mathrm{An}$ example in which the welfare of future generations increases with $\xi$ is when all parameters are as in footnote 11, except for $\alpha$, that is set equal to 0.6.

${ }^{14}$ The result that in an OLG model intergenerational redistribution might lead to higher savings is neither novel, nor specific to our environment. Under some conditions, in the familiar Diamond's model, a tax on capital income whose proceeds are redistributed to the young also leads to faster
} 
The simple demographic structure of our model implies a perfect coincidence between young and entrepreneurs, and between old and financiers. Then it is obvious why entrepreneurs have higher saving rates. It should be clear, however, that the scope of our result goes way beyond this simple structure. In fact, it has been argued by many that entrepreneurs tend to have higher saving rates than the rest of the population. ${ }^{15}$ Our message is that as long as a worsening of investor protection induces a redistribution from individuals with low marginal propensities to save (outside investors) to individuals with high propensities (entrepreneurs), the correlation between investor protection and growth is not as trivial as a partial equilibrium model of investment would make us think. The reason, once again, is that such redistribution is going to have a positive effect on the supply of capital.

\subsection{Robustness of the results: An assessment}

A particular feature of our model is that the fraction of entrepreneurs in the economy is fixed. All projects are financed at all times, regardless of the level of investor protection. This may matter. One can think of simple variations of our setup, in which changes in the level of investor protection have an impact on capital accumulation via changes in the number of entrepreneurs.

In Appendix $\mathrm{C}$ we consider one such variation. We allow production to depend on labor as well as capital, and young individuals to choose whether to become entrepreneurs or to work for a wage; the fraction of entrepreneurs is an equilibrium outcome. Poorer investor protection can now be accommodated to some degree by an increase in the fraction of entrepreneurs. This increase will lower the capital available to each entrepreneur. In turn, this will mitigate the increase in risk borne by the entrepreneurs themselves, and so lower their expected income. We show that the economy does adjust along this new margin. However, in general, the negative association between investor protection and capital accumulation still holds.

A different model could allow for credit rationing. Consider our baseline model, but assume that running a project requires incurring a fixed cost and that individuals are heterogeneous with respect to its magnitude. If an agent's cost is too high for his project to be financed, he will resort to a subsistence activity that yields a constant outcome. In this environment an improvement in investor protection may increase the

capital accumulation. However, the implications for other endogenous quantities such as interest rate and welfare, are radically different. We thank an anonymous referee for making this observation. According to us, the novelty of our contribution lies in the mechanism that triggers the redistribution.

${ }^{15}$ For example, see Gentry and Hubbard (2000). 
size of the entrepreneurial sector. The net effect on capital accumulation, however, is still uncertain. With a larger entrepreneurial sector each entrepreneur will bear less risk and will receive a lower return. In turn, this implies that he will save less.

Our conclusion is that the supply effect is more general than might be thought based only on our baseline model.

In the introduction, we mentioned that our paper is not the first to investigate the effect of moral hazard on capital accumulation. Among the studies that have addressed the same question, the one by Khan and Ravikumar (2001) is most similar to ours. Thus it is striking that their results are very different. Also in their setup, the introduction of moral hazard leads to imperfect risk-sharing. Its effect on capital accumulation, however, is of the opposite sign. In our framework the positive impact on savings that is associated poorer risk-sharing, is induced by a redistribution of resources to the advantage of agents with higher propensity to save. By assuming that agents are infinitely-lived, Khan and Ravikumar (2001) rule out this mechanism. In their setup, there is no distinction between entrepreneurs and owners of capital. It appears that some heterogeneity in the propensity to save is a necessary condition for a model with infinitely-lived agents to generate results qualitatively similar to ours. Finally, note that while we focus on short-term contracts, Khan and Ravikumar (2001) allow for long-term contracts. Short-term contracts ignore the adverse effect that higher savings today (higher capital tomorrow) has on the provision of incentives for future generations. As discussed in Appendix A, long-term contracts do take this effect into account. In the same appendix we show that even in an OLG model, if there exist infinitely-lived institutions that provide individuals with lifetime optimal risk sharing and financing contracts, then moral hazard invariably leads to lower capital accumulation. We also argue that such contracts will be feasible only under very restrictive assumptions.

\section{The role of international capital mobility}

In this section we consider a small open economy with no restrictions on capital flows. We allow the old to lend to foreigners, and the intermediaries to borrow from abroad. The interest rate is simply the rate prevailing internationally, and any difference between domestic demand and supply of capital is closed by an instantaneous flow of capital. Indeed, the economy is always in steady state.

Since the world-wide supply of capital is infinitely elastic, the general equilibrium 
effect on supply is absent. Poorer investor protection invariably translates into domestic entrepreneurs demanding less capital. In turn, this implies a lower domestic supply of capital and lower steady state levels for capital and output.

Let $k^{d}$ be the capital demanded by domestic intermediaries, and employed in production, and let $k^{s}$ be the total capital supplied by the currently old generation. The difference $k^{s}-k^{d}$ corresponds to the net outflow of capital from the domestic economy, i.e. to the deficit on the capital account. Proposition 3 establishes that, provided the level of investor protection is beyond a certain threshold, poorer investor protection is associated with a larger deficit (lower surplus) on the capital account.

Proposition 3 There exist unique capital levels $k^{*}$ and $k^{* *}$, with $0<k^{* *}<k^{*}$, such that:

1. If $k^{d} \lessgtr k^{*}$ then $k^{s}-k^{d} \gtrless 0$;

2. If $k^{d} \lessgtr k^{* *}$ then $\frac{\partial\left(k^{s}-k^{d}\right)}{\partial \xi} \lessgtr 0$.

Proof. 1. Given a level of capital in domestic production $k^{d}$, we know from Section 3 that the level of capital supplied by the old generation is determined by the market-clearing condition $k^{s}=k^{s}\left(k^{d}\right) \equiv \kappa(r)\left[\bar{z} f\left(k^{d}\right)-(r+\delta) k^{d}\right]$, for some function $\kappa$. Since $\kappa(r)$ is a constant, $k^{s}\left(k^{d}\right)$ has the same shape as the intermediary's budget constraint, which was introduced previously. Figure 7 plots this function together with the 45 degree line. Notice that the vertical difference between $k^{s}\left(k^{d}\right)$ and the 45 degree line corresponds to the net capital outflow from the domestic economy. Define $k^{*}$ such that $k^{*}=k^{s}\left(k^{*}\right)$. It follows that $k^{*}>0$ exists and is unique. The first part of the proposition then follows.

2. Note that, by Proposition $1, k^{d}=D(r, \xi)$ is strictly decreasing in $\xi$. Therefore $k^{d} \leq D(r, 0) \cdot{ }^{16}$ Now define $k^{* *}$ such that $\partial k^{s}\left(k^{* *}\right) / \partial k^{d}=1$. It follows that $k^{* *}>0$ exists and is unique. Clearly $k^{* *}$ maximizes $k^{s}-k^{d}$, and $k^{* *}<k^{*}$. For $k^{d} \lessgtr k^{* *}$ we have $\partial\left(k^{s}-k^{d}\right) / \partial k^{d} \gtrless 0$. Since $k^{d}$ is strictly decreasing in $\xi$, the second part of the proposition follows.

In Section 3 we showed that poor investor protection can have a positive effect on savings via the adjustment of the interest rate. For a closed economy, this effect can be stronger than the negative effect on capital demand. In this section, we considered

\footnotetext{
${ }^{16}$ Without loss of generality, Figure 7 depicts the case in which $k^{*}<D(r, 0)$. Depending on $r$, in particular, it is possible to have $k^{*} \geq D(r, 0)$ as well.
} 


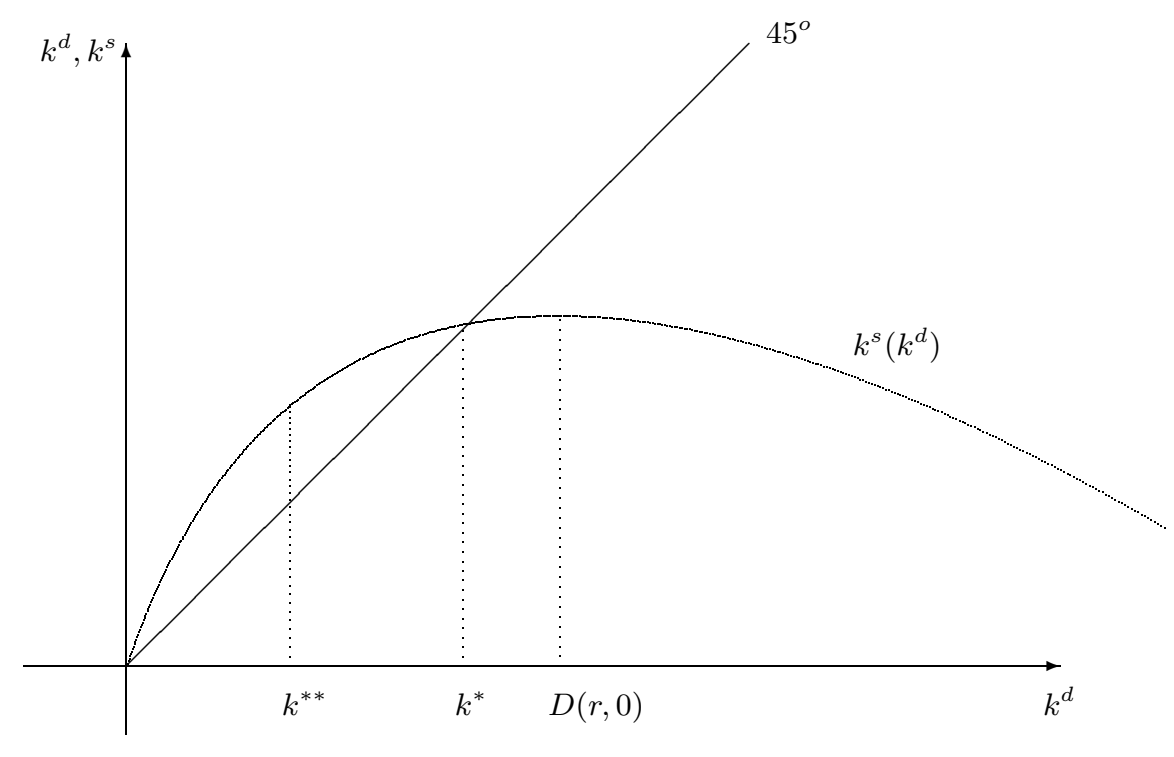

Figure 7: Net Capital Flows.

a small open economy with unrestricted capital flows. The general equilibrium effect vanishes, leaving only the demand effect. Therefore better investor protection is always associated with higher savings. Better investor protection also implies higher welfare for all generations.

\section{Data}

In this section we provide empirical support for the key implications of our model. We measure investor protection with the indicators introduced by La Porta et al. (1998). Such indicators quantify explicit protections awarded to shareholders and creditors by corporate, bankruptcy, and reorganization laws, as well as the quality of law enforcement. We focus on four of them. The variable $C R$ is an index aggregating different creditor rights in firm reorganization and liquidation upon default. The indicator anti-director rights, $A R$, and the dummy one share-one vote, $O V$, are two indices of shareholder rights geared towards measuring the ability of small shareholders to participate in decision-making. Finally, the index rule of law, $R L$, proxies for the quality of law enforcement. The variables are described in detail in La Porta et al. (1998). 


\subsection{Risk sharing}

The analysis in Section 3.2 implies that when investor protection is imperfect, companies' insiders face an incentive to expropriate resources from outside investors. This incentive is stronger the poorer is the level of investor protection. Investors' optimal response to the adverse incentives induced by imperfect protection is to require repayment terms that are less tied to the state realizations. In other words, our model predicts that in countries characterized by better investor protection, insiders should be able to transfer a larger share of their idiosyncratic business risk to betterdiversified outside investors. Our purpose here is to explore the empirical association between investor protection and risk sharing. In the absence of a direct measure of risk sharing, we study how capital structure and ownership concentration, respectively, vary with the levels of investor protection in the cross-section of countries. The reason is that, all else being equal, the risk borne by company insiders should be larger, the larger the company's leverage and the higher their ownership stakes. In fact, based on the features of standard debt and equity contracts, shareholders' risk is increasing in leverage. The portion of this risk that shareholders actually bear depends on how diversified their portfolios are. All else equal, the level of diversification will be lower the higher their ownership stake. To summarize, we conjecture that insiders' risk sharing is poorer in countries where debt accounts for a larger fraction of external finance and where ownership concentration is higher.

For a subset of the countries included in the investor protection data set, the Financial Structure database assembled by Beck, Demirgüç-Kunt, and Levine includes data on the value of outstanding debt and equity in the years 1990 through $1996 .{ }^{17} \mathrm{We}$ use this data to compute the average fraction of external finance that is accounted for by debt. This fraction is negatively correlated with the indicators of investor protection. The correlation coefficients are -0.65 for $A R$, and -0.39 for $C R$. The corresponding $p$-values are 0.0358 and 0.0002 , respectively. We interpret these findings

\footnotetext{
${ }^{17}$ The value of debt is computed by summing the values of the variables PRIVATEB (total amount of outstanding domestic debt securities issued by private domestic entities) and PRIVO (claims on private sector by deposit money banks and other financial institutions). The calculation of external equity requires a little extra care. La Porta et al. (1998) show that for most countries a large portion of the equity of public companies is actually held by insiders. Therefore, adopting stock market capitalization as a measure of external equity finance would introduce a bias in our computations. We address this issue by adopting the methodology of La Porta et al. (1997). For each of the countries, La Porta et al. (1998) report the median fraction of equity that is cumulatively held by the three largest shareholders in the ten largest nonfinancial domestic firms. In our calculations, we assume that a fraction of the total equity equal to this median is actually held by insiders.
} 
as empirical support for our prediction. ${ }^{18}$

We now turn to ownership concentration. Our model implies that ownership should be more concentrated in countries with poorer protection. This is exactly what is found by La Porta et al. (1998). They report a negative correlation between their indicators of investor protection and a measure of ownership concentration given by the mean (or median) combined equity stake for the three largest shareholders of the 10 largest nonfinancial, domestic, totally private and publicly traded companies.

\subsection{Investor Protection, International Capital Mobility, and Growth}

The second key implication of our model is that the effect of investor protection on growth should depend on international capital mobility. The analysis carried out in Section 3 implies that if we were to observe two countries, completely closed to capital flows, that differed only in terms of investor protection, then we should observe the economy with poorer protection to grow faster. That is, for perfectly closed economies, investor protection should have a conditional negative effect on growth. In Section 4 we showed that, in the polar case in which a country is completely open to capital flows, different levels of investor protection have no effect on rates of return. For perfectly open economies our model implies that countries with better protection should have higher steady states.

Most national economies are better described by models allowing for some, though incomplete restrictions on capital flows, rather than by either of the extremes considered above. As long as some restrictions are in place, the domestic interest rate is not completely determined by the rate prevailing abroad, and the model displays a transition to the steady state. Lower levels of investor protection are still reflected in lower paths of the interest rate. Most importantly, the adjustment of the interest rate and the strength of the general equilibrium effect on supply will be larger, the tighter are the constraints on capital flows. Thus our theory predicts that the positive effect of investor protection on growth should be larger for countries that impose milder restrictions on capital flows.

Our goal is to determine whether the data is consistent with the empirical prediction just outlined. We first conduct a statistical analysis of cross-sectional data on

\footnotetext{
${ }^{18}$ Our decision to combine bonds and bank loans in one measure of debt may bias our results. The reason is that the risk sharing properties of the two instruments might be different. We refer to the view that sees banks as effective risk-sharing providers. As an alternative measure of leverage, we considered the ratio between the value of outstanding bonds and total market finance (i.e. the sum of bonds and equity finance). We continue to find a robust negative correlation between this measure and the different indicators of investor protection.
} 
growth, investor protection, and openness, and then explore the development experiences of South Korea and India.

\subsubsection{Cross-country evidence}

To build a measure of restrictions on capital movements we follow Alesina et al. (1994) and Lewis (1996). For each country, we construct a time-series dummy based on the IMF's Annual Report on Exchange Arrangements and Exchange Restrictions. The dummy variable takes the value of 1 for a given country in a given year if the IMF finds evidence of restrictions on payments on capital transactions for that countryyear pair. Such restrictions include both taxes and quantity restrictions on the trade of foreign assets. We compute the average of this dummy over the sample period to obtain a measure of the fraction of time each country imposed restrictions on international capital transactions; this is our variable $R C T$. There are few countries for which the dummy varies significantly over time. $R C T$ is equal to one for just over one-third of the countries in our data, and is roughly uniformly distributed for the rest. Since $R C T$ does not capture either the kind or the severity of capital market restrictions imposed, or even whether the type of restrictions imposed remain constant over time, it is a very rough measure of restrictions on capital transactions. ${ }^{19}$

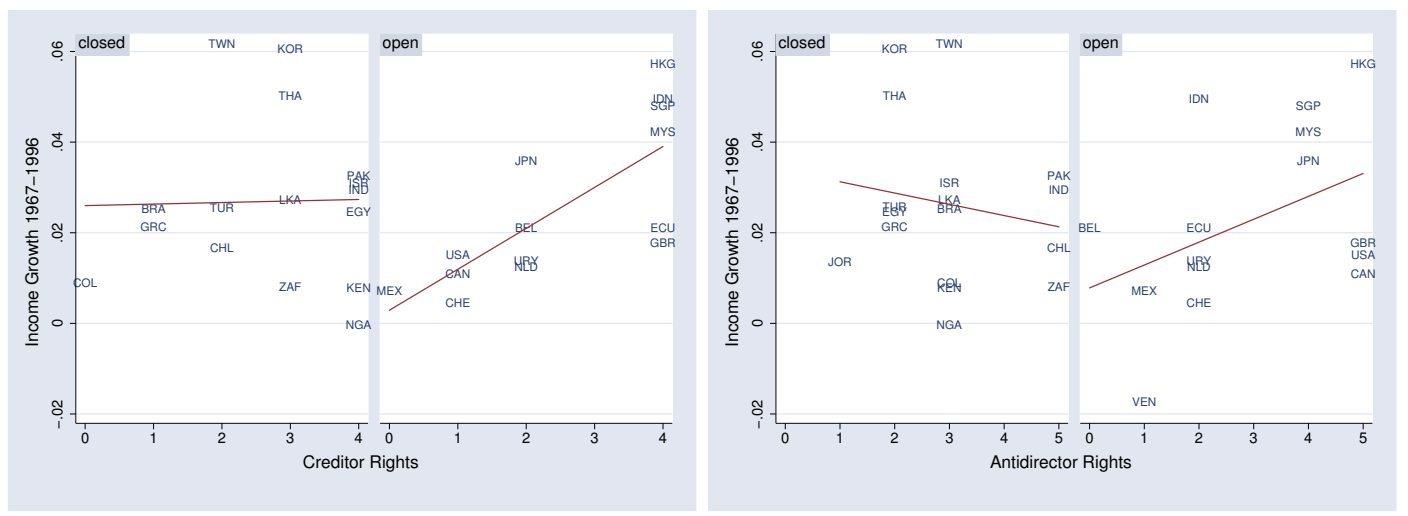

Figure 8: Output Growth and Investor Protection.

\footnotetext{
${ }^{19}$ Recently, Dennis Quinn has constructed alternative measures of international financial regulations by coding the provisions of domestic and international laws of 64 countries from 1950 to 1997. (See Quinn (1997) for a detailed illustration of his methodology). Quinn's measure of capital market restrictions, CAPITAL, accounts for the severity of the restrictions at the cost of a greater discretion in construction of the indicator. We have repeated our analysis, substituting CAPITAL for RCT, and find that the results are very similar. Given the positive correlation between the two measures, this is not too surprising.
} 
Figure 8 illustrates how the relation between investor protection and growth varies across closed and open economies. In the two panels we plot two measures of investor protection against the growth rate of GDP per worker for two sets of countries: those with values of RCT that belong to the first quartile of the cross-sectional distribution of this variable ("open" countries), and those whose values fall in the top quartile ("closed"). ${ }^{20}$ Our model predicts that the correlation between investor protection and growth should be higher among open economies. The figures are consistent with this prediction. For closed economies, the slopes are not significantly different from zero. $^{21}$

Figure 8 also identifies the countries that are mostly responsible for the sample correlations. Among open economies, the fast growers have the right institutions: Hong-Kong, Malaysia, Indonesia, and Singapore. Among the closed ones, instead, there are several with good institutions that do not grow nearly as fast. What is striking is that the fast growers among the closed economies are those with poor investor protection: Korea, Taiwan, and Thailand. Obviously we are not the first to partition East-Asian economies in fast- and slow-growers. Table 3-14 in Maddison (2001) does it in a very effective way. What we find remarkable is the way in which the differences in growth rates are associated with differences in investor protection and openness, a way that is quite consistent with our theory.

In order to condition on other potential sources of cross-country variation in growth rates, we now consider a standard growth regression framework. Our regressors are the indicators of investor protection and of restrictions on capital transactions,

\footnotetext{
${ }^{20}$ The IMF does not provide data on capital restrictions for Taiwan. Nevertheless, based upon the capital account liberalization chronology for this country, described in detail in Kaminsky and Schmukler (2003), we classify it as closed and include it in the plots. As it is the case for Korea, Taiwan completed the liberalization of international capital flows only at the end of the 1990's. The significance of our results is not sensitive to the inclusion of Taiwan; indeed, we do not include it in our regression analysis.

${ }^{21}$ In Figure 8 we restrict our attention to the relationships between growth and the variables $A R$ and $C R$, respectively. We think that these are the two indicators that are more likely to reflect the level of overall investor protection. However, we recognize that the role of $R L$, which proxies for the level of law enforcement, may also be important. Therefore we computed a summary measure of protection using principal components. In our case, the principal components are four orthogonal vectors that are computed as linear combinations of the four series $A R, C R, R L$, and $O V$. The summary measure is the weighted average of the components, where each weight is the proportion of the variation in the original series that is explained by the related component. Plotting the growth rates against the new measure yields results that are similar to those illustrated in Figure 8. That is, for open economies, the correlation coefficient is significantly higher. In the regression analysis that follows we consider all four protection indicators.
} 
as well as their interactions:

$$
G R_{i}=\alpha+\phi^{\prime} I P_{i}+\gamma R C T_{i}+\varphi^{\prime}\left(I P_{i} \times R C T_{i}\right)+\theta^{\prime} X_{i}+\varepsilon_{i}
$$

where $G R_{i}$ is the average annual growth rate of income for country $i, I P_{i}$ is a set of indicators of investor protection, $R C T_{i}$ is a measure of restrictions on capital transactions, $X_{i}$ is a vector of other conditioning variables believed to be important to account for growth, and $\varepsilon_{i}$ is the error term. ${ }^{22}$

When the restrictions $\gamma=0$ and $\varphi=0$ are imposed, the model relates investor protection to income growth without any reference to the mechanism through which the former influences the latter. In other words, the restricted regression summarizes the combined evidence of La Porta et al. (1997), King and Levine (1993a,b), and others in a reduced-form way. Their finding that investor protection fosters financial market development, which in turn is positively associated with growth, corresponds to a significantly positive estimate of $\phi$.

Our theory suggests that the overall positive effect of investor protection on growth may be decomposed into a positive effect (our partial equilibrium demand effect), captured by $\phi$ in the unrestricted regression, and a negative effect that depends on the restrictions on international capital movements (our general equilibrium effect on supply), captured by $\varphi$.

In deciding which variables to include in $X_{i}$ we choose to remain anchored to our theory as much as possible. Therefore we only include the natural logarithm of initial income as a conditioning variable. ${ }^{23}$ Our income data is real GDP per worker from the Penn World Tables, version 6.1. Our set of countries corresponds to the 49 in La Porta et al. (1998) except for Germany, which has missing income data for most years, and for Jordan and Venezuela, which have missing data on creditor rights. In the unrestricted regression we also drop Switzerland, Zimbabwe, and Taiwan, because the IMF did not include them in its survey in every year. The time span of our sample is from 1967 to 1996, the largest possible for all 49 countries in the La Porta et al. (1998) data set.

\footnotetext{
${ }^{22}$ Notice that our specification is more general than one that uses income level as dependent variable. As noticed by Mankiw et al. (1992), if the dependent variable was the level of income instead of its growth rate, we would implicitly assume that countries deviate only randomly from their steadystates. Our approach can also account for out-of-steady state dynamics.

${ }^{23}$ The results in Table 1 did not change in any important way when we included in $X_{i}$ schooling measures based upon the Barro and Lee (1996) data set (we tried both the log of average secondary schooling and the log of average total schooling). With log schooling and log initial income, our $X_{i}$ becomes the "simple information conditioning set" considered by Beck et al. (2000a,b).
} 
Table 1: Output Growth, Investor Protection and Capital Restrictions

\begin{tabular}{lcc}
\hline \hline \multicolumn{2}{l}{ Dependent Variable: Average annual growth rate of real GDP per worker 1967-1996 } \\
\hline Log Real GDP per worker 1967 & $-0.01392^{b}$ & $-0.0094^{c}$ \\
& $(0.00568)$ & $(0.00562)$ \\
One share-one vote (OV) & $0.00854^{c}$ & 0.00158 \\
& $(0.0046)$ & $(0.0085)$ \\
Antidirector rights (AR) & -0.00048 & 0.00199 \\
& $(0.00125)$ & $(0.0017)$ \\
Creditor rights (CR) & 0.00149 & $0.00998^{a}$ \\
& $(0.00174)$ & $(0.00353)$ \\
Rule of law (RL) & $0.004195^{a}$ & 0.00366 \\
& $(0.00134)$ & $(0.00237)$ \\
Restrictions & & $0.04768^{c}$ \\
on capital transactions (RCT) & & $(0.02538)$ \\
OV $\times$ RCT & & 0.0091 \\
& & $(0.01362)$ \\
AR $\times$ RCT & & $-0.0053^{c}$ \\
& & $(0.00298)$ \\
CR $\times$ RCT & $-0.0103^{b}$ \\
RL $\times$ RCT & & $(0.00422)$ \\
Constant & -0.00101 \\
& $0.1209^{b}$ & $(0.00237)$ \\
Number of countries & $(0.04892)$ & 0.054 \\
Adjusted $R^{2}$ & 46 & $(0.0546)$ \\
\hline
\end{tabular}

Note: White robust standard errors in parenthesis.

Sources: Heston et al. (2002), La Porta et al. (1998) and IMF (Annual Report on Exchange Arrangements and Exchange Restrictions, 1967-1996).

${ }^{a}$ Significant at $1 \%$; ${ }^{b}$ Significant at $5 \%$; ${ }^{c}$ Significant at $10 \%$.

We report our results in Table 1. The first column refers to the restricted regression. Consistent with the existing literature, we find that two of the measures of investor protection have significantly positive coefficients. The estimated impact of investor protection is large. One standard deviation increase in $R L$ is predicted to increase the growth rate of income by $1.12 \%$, i.e. almost $50 \%$ of the average annual growth rate in the sample, $2.3 \%$. Since we find a significant effect when conditioning on initial incomes, we conclude that countries with better investor protection also tend to have higher income levels (not only growth rates).

The second column presents estimates of the unrestricted model. All four coefficients of the investor protection variables are positive (although with varying degrees of statistical significance) and three of the coefficients of the interaction terms are negative. The fourth coefficient is positive, but the $p$-value for the hypothesis that it is equal to zero is 0.51 . These results are consistent with our theory in the following 
sense. If a country has never imposed restrictions on capital transactions over the relevant time period, so that $R C T=0$, then the data shows that investor protection is clearly positively associated with growth. To the extent that $R C T=0$ corresponds to the highest degree of openness in the data, our model suggests that we interpret the positive estimates of $\phi$ as capturing the partial equilibrium effect on demand. As $R C T$ increases towards 1 , however, the regression results show that the overall effect of investor protection on growth diminishes. This is consistent with an increased importance of the general equilibrium effect on supply.

Creditor rights seem to have the largest impact on growth. The coefficients of $C R$ and $C R \times R C T$ are statistically significant, and the $p$-value for the null hypothesis that they are jointly insignificant is 0.028 . In the absence of capital market restrictions (i.e. $R C T=0$ ), a one standard deviation increase in $C R$ is predicted to increase the growth rate by $1.38 \%$. At the other extreme (i.e., $R C T=1$ ), the predicted effect of the same change is actually a small decline in growth, $-0.04 \%$; the supply effect is stronger than the more familiar demand effect. The strength of the interaction with $R C T$ explains why, in the restricted regression, $C R$ appeared unimportant for growth. $^{24}$

The findings are similar, but less statistically and economically significant, for the impact of $R L$. The coefficients of $R L$ and of its interaction with $R C T$ are not individually statistically significant, but the hypothesis that both are zero has a $p$ value of 0.09. A one standard deviation increase in $R L$ is predicted to increase growth by $0.97 \%$ when $R C T=0$ and by $0.71 \%$ when $R C T=1$. This is consistent with a significant positive coefficient in the restricted model. ${ }^{25}$

The reader may wonder whether the regression results are driven by outliers. In Figure 9 we plot the partial relationships between income growth and the interaction terms $A R \times R C T$ and $C R \times R C T$, respectively. It appears that outliers do not play any significant role. The sign of the relationships seem to hold for the broad sample of countries.

One would also like to know whether our results are robust to the choices of regression specification and data set. In this respect, it is helpful to recall the results of other recent studies, namely Arteta et al. (2001) and Chinn and Ito (2002), that

\footnotetext{
${ }^{24}$ The fact that $O V$ is marginally significant in the first regression also appears to be an artifact of the restrictions imposed. In the unrestricted model, the coefficients of both $O V$ and $O V \times R C T$ are insignificant, and the $p$-value for the hypothesis that both are zero is 0.24 .

${ }^{25}$ The results also suggest the effect of $A R$ on growth operates through the supply effect, but the evidence is weak. The coefficients on $A R$ and $A R \times R C T$ are small and statistically insignificant: the hypothesis that they are both zero has a $p$-value of 0.22 .
} 

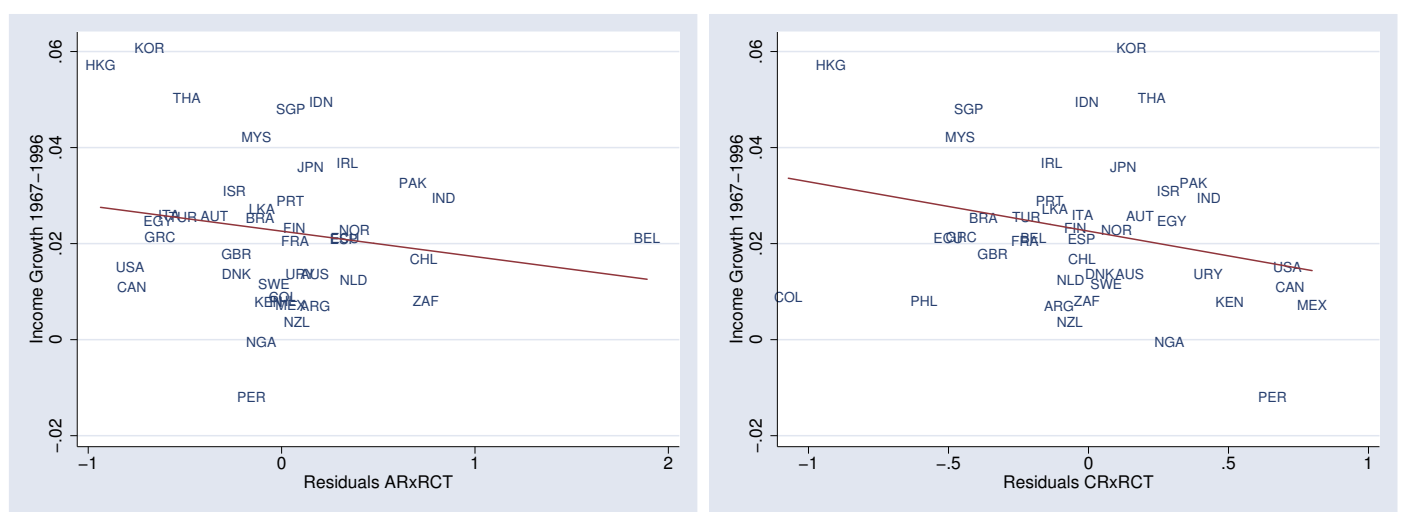

Figure 9: Conditional relationship between income growth and interaction term

employ alternative specifications (in particular, different conditioning variables) and data sets. Differently from ours, the ultimate goal of these studies is to investigate the statistical relationship between capital account liberalization and various measures of development, and to understand whether such relationship depends on the quality of institutions. ${ }^{26}$ In spite of this difference, their results can be reinterpreted as showing that the magnitude of the (positive) impact of investor protection on development depends negatively on the extent of capital restrictions.

\subsubsection{India versus South Korea}

We now take a closer look at the development experiences of two countries: South Korea and India. Korea is one of the post-WWII growth miracles. During our sample period, its per-capita GDP grew at an astonishing 6.06\% annual compounded rate, among the highest in the world. Despite a lower initial level of PPP-adjusted percapita GDP, India grew only at a $2.95 \%$ rate, a slightly above average performance in our sample. What accounts for such difference? As pointed out by Maddison (2001), country growth performances in Far East Asia in the second post-war period have varied widely. A large literature has tried to explain this heterogeneity. Most studies argue that the variation was caused either by differences in government policies, or by other idiosyncratic factors. We chose to focus on Korea and India because there is ample evidence suggesting that, at least from a qualitative point of view, growthpromoting policies enacted in these two countries were very similar. We suggest that the relevant difference between the two is in terms of institutions and, in particular,

\footnotetext{
${ }^{26}$ The dependent variable in Chinn and Ito (2002) is the change in indicators of financial market development rather than the growth rate of income.
} 
in terms of investor protection.

India and Korea appear to differ greatly in terms of investor protection. According to legal scholars, India, a British colony until 1947, belongs to the common-law family. Korea's laws and institutions, instead, are inspired by the civil law tradition, and are modelled on the German example. As a result, Korea ranks significantly lower than India in terms of both the $A R$ and $C R$ indicators. ${ }^{27}$ These observations lead us to conclude that India is more likely than Korea to provide outside investors with effective protection from the exploitation of insiders.

Both the Korean and the Indian governments have played very active roles in the allocation of credit to firms. A common theme of their interventions in the financial sector has been the creation of rents for specific manufacturing sectors. Such rents were created by inducing banks and other financial intermediaries to keep the returns to investors artificially low in order to provide selected industries with credit at very favorable terms. ${ }^{28}$ This policy was feasible thanks to very tight controls on capital flows. ${ }^{29}$ Such controls were gradually eased during the last years of our sample period. However, there is no doubt that domestic investors were barred from investing abroad during most of the period. Domestic capital was kept captive. ${ }^{30}$ Referring to Korea, Dornbush and Park (1987) argues that “... By paying depositors low real interest rates and by controlling capital outflows, the government implicitly taxed depositors, then channelled the proceeds to favored sectors for investment." Then, why did such a policy, often referred to as one of financial repression, succeed in promoting growth in Korea but fail in India?

The literature provides several tentative answers to this question. Cho and Vittas (1995), for example, argue that the Korean government made better choices in terms

\footnotetext{
${ }^{27}$ However, India scores slightly lower in terms of law enforcement. Our impression, based upon anecdotal evidence, is that investors are overall better protected in India. When we performed the principal component analysis described in footnote 21, India did come out has having a better summary index of investor protection than Korea (and also better than Thailand and Taiwan).

${ }^{28}$ There is ample consensus on the view that the credit policies enacted in India and Korea were very similar, at least in spirit. For example, according to Cho and Vittas (1995), this is the general view that emerged from the World Bank research project titled "Effectiveness of Credit Policies in East Asian Countries".

${ }^{29}$ Both Korea and India are in the first quartile of the cross-country distribution of our measures of openness to international capital flows. The IMF finds that both countries had restrictions in place in all years of our sample. Therefore our variable RCT takes value 1 (the maximum value) for both. The measure proposed by Quinn yields a consistent characterization. The average of his indicator CAPITAL, which ranges from 0 (completely closed) to 4 (perfectly open), is 1.4 for India and 1.7 for Korea.

${ }^{30} \mathrm{~A}$ further confirmation that this was the case for Korea is provided by Dornbush and Park (1987). They report data from the IMF's International Financial Statistics showing that in the 80's nonbank Korean residents had almost no external deposit holdings.
} 
of which sectors to privilege. Others have argued that, differently from their Indian counterparts, Korean firms have been subject to foreign competition, with the result of achieving higher productive efficiency. Our stand is that these explanations fail to account for another crucial difference between the two development experiences: the one between saving rates.

A high national saving rate is a well-known feature of the Korean growth experience, and it helps explain how Korea was able to sustain a very high investment rate since the late 1960's. Precisely, Young (1995) identifies capital accumulation as the key ingredient behind the tremendous growth of Korea's GDP. The average Korean saving rate in our sample was $28 \%$, while the rate for India was just $19 \% .{ }^{31}$ Moreover, Korea's rate was substantially higher in any single year. The size of the gap between saving rates looks even more dramatic when we consider that, according to several measures, average real interest rates have been higher in India than in Korea. The IMF's International Financial Statistics (IFS) provide yearly measures of several key nominal interest rates for developing countries. Unfortunately, rates on time deposits are available only for Korea. Dornbush and Park (1987) comment on this data is that "... Although Korea is often cited as an example of successful financial liberalization with high and positive real interest rates mobilizing financial resources for investment and growth, ... real rates have not been high, except in 1965-69,... The relationship between saving and interest rates remains unresolved in Korea, just as everywhere else." The IFS data set, however, does contain information on prime nominal annual lending rates of commercial banks for both countries. Real rates (i.e. nominal rates adjusted for realized inflation) were, on average, $7 \%$ in India and only $3.2 \%$ in Korea. One problem with this data is that it is limited to 17 observations (from 1980 to 1996). An alternative is to follow Hsieh (2002) and look at discount rates, for which we have data for the whole sample period in the IFS. ${ }^{32}$ We find discount rates in India to be on average significantly higher than in Korea: $2.2 \%$ versus $-0.56 \%$. How to reconcile the behavior of saving rates with observed interest rates? Our theoretical analysis suggests that lending rates were lower (rates of return to entrepreneurs were higher) in Korea because risk sharing was poorer.

\footnotetext{
${ }^{31}$ We computed the saving rate in a single year exactly as in Carroll et al. (1994). It is the ratio of nominal saving to nominal GDP, where nominal savings are given by nominal GDP minus the sum of nominal private consumption and nominal government consumption. Nominal values are in domestic currency. The data is drawn from the national account information contained in version 6.1 of the Penn World Tables.

${ }^{32}$ For Korea, in particular, Hsieh (2002) finds discount rates to be approximately equal to deposit rates.
} 
In both countries, the purpose of the government was to entice entrepreneurs to invest, by allowing them to borrow at low rates. Our point is that in setting those rates, either government must have taken demand conditions into account. The higher the undiversifiable risk entrepreneurs were subject to, the lower the rates needed to be in order to accomplish the government's objective. Since, as we argue below, the institutional framework in India provided entrepreneurs with better opportunities for risk-sharing, the latter required a lower return on investment than their Korean analogues. This implies that the Indian government could allow interest rates on loans to be higher than in Korea, thereby limiting the extent of the income redistribution in favor of the entrepreneurial sector. Finally, this contributed to keep the saving rate in India relatively low.

We have already argued that measuring risk sharing is not an easy task. However, the proxies introduced in Section 5.1 suggest that Korean entrepreneurs had a harder time sharing business risk with the rest of the population. Consider capital structure choices first. Korean firms' leverage has been much higher than their Indian counterparts' throughout our sample period. ${ }^{33}$ It has been repeatedly argued in the literature that the Korean government kept ready to avoid that this resulted in (possibly inefficient) bankruptcies. However, even if firms were provided insurance against extreme events, a larger fraction of fixed income claims must have implied greater income risk for shareholders. The fraction of this risk that was actually borne by them depends on their ability to diversify their portfolios. In order to assess the diversification opportunities available to insiders, we consider data on ownership concentration. In general, the presence of pyramidal schemes and intra-group cross shareholdings makes it inaccurate to measure cash-flow rights by simply considering direct shareholdings. ${ }^{34}$ When the purpose is to compute the total cash-flow rights of ultimate owners, direct cash flow-rights constitute only a lower bound. That is, the presence of both pyramids and cross-holdings lead to the underestimation of owner-

\footnotetext{
${ }^{33}$ This fact has been documented by several authors, using different data. Claessens et al. (2000) compute leverage ratios using data drawn from the annual reports of the companies listed on the major stock exchanges, as gathered by the Worldscope Database. They find that during the period 1988-96 Korean companies were the most leveraged in their large sample of developed and developing countries. This ranking is preserved even when the last two years of the sample, characterized by an accelerated debt build-up in Korea, are excluded. Indian companies instead lie in the left tail of the cross-country distribution of leverage. A similar picture emerges when we consider the data on the ratio of debt to external finance introduced in Section 5.1. The fraction of total external finance accounted for by debt is $83 \%$ in Korea and $67 \%$ in India.

${ }^{34} \mathrm{~A}$ pyramidal structure allows an individual to have cash-flow rights on a company via ownership of a third company. The simplest case is the one in which a person has an ownership stake in a firm, which in turn holds a stake in a third company. The simplest example of cross-shareholdings is given by the case in which two companies hold ownership stakes in each other.
} 
ship stakes. We argue that in the case of Korea, the bias introduced by using direct rights is particularly large. The reason is that cross shareholdings are a pervasive feature of chaebols, Korean business groups. Nam et al. (2001) find that in 1997 the average direct ownership fraction of the largest shareholder of the 10 biggest chaebols was a mere $10.29 \%{ }^{35}$ When properly accounting for cross shareholding, Nam et al. (2001) find that the figure climbs to a staggering $39.58 \%$. The available evidence suggests a very different scenario for Indian firms. Goswami (2002) writes that in India "... During the industrial expansion of the 1970 s and 1980s, the average share ownership of the controlling groups declined to 15 percent." Bertrand et al. (2002) report that in their sample the average equity stake of directors was $16.7 \%(7.45 \%$ for business groups and $22.99 \%$ for stand-alone firms). ${ }^{36}$ Unfortunately for our analysis, these figures refer to direct holdings only. This makes it hard to compare them with the numbers reported by Nam et al. (2001) about Korean firms. However, if, as it seems plausible, in the Bertrand et al. (2002) data set the directors include the largest shareholders, their indirect cash-flow rights must be lower than the direct ones. Therefore, $14.9 \%(2 \times 7.45 \%)$ constitutes an upper bound for the total cash-flow rights of directors in Indian business groups. Our conclusion is that, at least for large groups, the concentration of cash flow rights was much higher in Korea than India.

The difference in risk sharing that we have documented is clearly consistent with our theory. Given the evidence on investor protection, our model predicts that Indian entrepreneurs should be able to share their business risk with the population, to a larger extent than their Korean counterparts.

To summarize, we believe that the comparison of India's and South Korea's development experiences illustrates quite well the key mechanism at work in our model. The evidence tells us that during the sample period both countries have placed considerable restrictions on capital flows, and that India has better protected the interests of investors than Korea. In turn, this difference in investor protection seems to be reflected in a substantial difference in the opportunities for risk diversification available to entrepreneurs in the two countries. The data also tells us that during the same period Korea grew much faster and had much higher saving rates than India, despite lower real interest rates. Our theory provides a rationalization for this set of findings.

\footnotetext{
${ }^{35}$ The result is consistent with what reported by La Porta et al. (1998). They find that the average direct ownership fraction of the three largest shareholders of the 10 biggest chaebols is $23 \%$.

${ }^{36}$ Bertrand et al. (2002) draw their data from Prowess, a database that includes annual report information for Indian companies between 1989 and 1999. Their sample contains about 18,500 firmyear observations.
} 
The purpose of both the Korean and the Indian government was to direct funds to the entrepreneurial sector at favorable terms, with the purpose of fostering investment in given industries. Real interest rates (returns to entrepreneurs) in Korea were lower (higher), because entrepreneurs faced more risk and therefore needed greater incentives in order to invest. In turn, this has implied the distribution of larger rents to the entrepreneurial sector. Finally, given the higher saving rate of entrepreneurs, this led to higher saving and faster capital accumulation.

\section{Conclusion}

In this paper we have introduced investor protection in the familiar two-period OLG model of capital accumulation. The level of protection afforded by financiers is measured by the cost a borrower would have to pay to misreport his cash-flow.

Our model produces several interesting implications. First, the structure of financial claims adjusts endogenously to changes in investor protection. We show that the risk sharing implied by optimal financing contracts is increasing in the level of protection. We find empirical support for this prediction. In countries where outside investors are better protected, equity claims are more prevalent, and firm ownership is less concentrated.

Second, we show that the overall effect of protection on capital accumulation can be decomposed into a positive effect on the demand for capital, and a negative general equilibrium effect on supply. The strength of the supply effect is greater the tighter are the restrictions on international capital mobility. Therefore, our model predicts that the positive effect of investor protection on growth should be larger for countries that impose lower restrictions on capital flows. We also find the data to be consistent with this prediction.

Our analysis can be extended in several potentially interesting ways. One is to introduce imperfect contract enforceability. This is of interest because some empirical measures of investor protection that appear to be associated with growth reflect the ability of the legal system to ensure that contracts are honored. It would also be interesting to introduce inside equity in the model, with the purpose of studying how the relative importance of inside and outside sources of finance vary with the degree of investor protection. Finally, endogeneizing the level of investor protection would open the possibility of understanding which features of actual economies can account for the large cross-country variation in this variable. 
We can also ask whether our analysis provides any insight into the recent wave of accounting-related scandals in the United States. Interpreting these events, journalists and commentators appear to describe the breakdown of a separating equilibrium in a simple adverse selection model. They argue that firms involved in the scandals were inefficient firms whose managers found it optimal to mimic the behavior of betterperforming companies. Our model suggests a very different interpretation. Suppose that the strong economy of the '90s led to an increase in what the model describes with $z_{h}$, but that incentives in contracts did not adjust immediately, or did not adjust enough. The model suggests that the firms involved in the scandals are actually the ones that had been performing well, and in which insiders found it profitable to appropriate some of the cash flows, disguising this appropriation by misreporting their accounting numbers. These firms are now (i.e., $t+1$ ) less valuable than they were earlier thought to be, not necessarily because they are less productive than expected (although this, too, would be consistent with the model, i.e., $z_{t+1}=z_{l}$ ). Instead, the reason is that contractual incentives lagging business conditions made taking a chance at appropriating large parts of firm resources optimal for firm managers. The effect of managers' expropriation on firm value was aggravated by the fact that such activity was inefficient, in that resources were used up in the hiding process, so that value concealed from investors did not translate one to one into higher managerial wealth. Accounts of the recent history of companies such as Tyco and Global Crossing lend plausibility to this idea. 


\section{A Long-term contracts}

In this section we characterize the allocation that would be chosen by a social planner that attaches a weight $\gamma^{t}, \gamma \in(0,1)$, to the utility of the generation born in period $t$. Importantly, we show that this allocation satisfies Rogerson (1985)'s condition on the intertemporal allocation of consumption. By construction, any market mechanism that relies on one-period financing contracts violates this condition. Therefore, the allocation that we have studied in Section 3 falls inside the Constrained-Pareto frontier. However, following an argument introduced by Allen (1985), we show that two-period contracts actually collapse to one-period arrangements if we introduce the possibility of unmonitored borrowing and lending.

Figure 10 describes the timing of the lifetime relationship between the planner and an individual born at time $t$. At the beginning of time $t$, the planner makes a capital advance $k_{t}$; its investment yields $z_{t} f\left(k_{t}\right)$. Then, the agent reports $z_{l}$ or $z_{h}$, and surrenders $z_{h} f\left(k_{t}\right)$ or $z_{l} f\left(k_{t}\right)$ to the planner. Finally, the planner assigns a lifetime consumption allocation $\left(c_{i, t}^{y}\left(\hat{z}_{t}\right), c_{i, t+1}^{o}\left(\hat{z}_{t}\right)\right)_{i=h, l}$. For every $t$, the pair $\left(c_{h, t}^{y}, c_{l, t}^{y}\right)$ denotes the consumption allocation intended for agents born at time $t$, conditional on high and low reports, respectively. The pair $\left(c_{h, t}^{o}, c_{l, t}^{o}\right)$ denotes the time $t$ consumption allocation intended for agents born at time $t-1$, again conditional on their report (issued at time $t-1$ ).

Given initial capital, $k_{0}>0$, the planner's optimization problem is:

$$
\begin{array}{r}
\max _{c_{0}^{o},\left\{k_{t+1},\left(c_{i, t}^{y}, c_{i, t+1}^{o}\right)_{i=h, l}\right\}_{t=0}^{\infty} \gamma^{-1} u\left(c_{0}^{o}\right)+\sum_{t=0}^{\infty} \gamma^{t}\left\{\rho\left[u\left(c_{h, t}^{y}\right)+\beta u\left(c_{h, t+1}^{o}\right)\right]+\right.}^{\left.(1-\rho)\left[u\left(c_{l, t}^{y}\right)+\beta u\left(c_{l, t+1}^{o}\right)\right]\right\},}
\end{array}
$$

subject to

$$
\begin{aligned}
\rho\left(c_{h, t}^{y}+c_{h, t}^{o}\right)+(1-\rho)\left(c_{l, t}^{y}+c_{l, t}^{o}\right) & =\bar{z} f\left(k_{t}\right)+(1-\delta) k_{t}-k_{t+1}, \\
u\left(c_{h, t}^{y}\right)+\beta u\left(c_{h, t+1}^{o}\right) & \geq u\left(c_{l, t}^{y}+\xi \Delta f\left(k_{t}\right)\right)+\beta u\left(c_{l, t+1}^{o}\right) .
\end{aligned}
$$

Equation (12) is the resource constraint. At all $t$, total consumption must be equal to production less gross investment. Condition (13) is the incentive compatibility constraint, conditional on high output. It is easy to show that (13) will always bind at the optimum. To see why, assume the contrary. Then the solution can be obtained ignoring this constraint altogether. By strict concavity of $u$, full insurance is necessary 


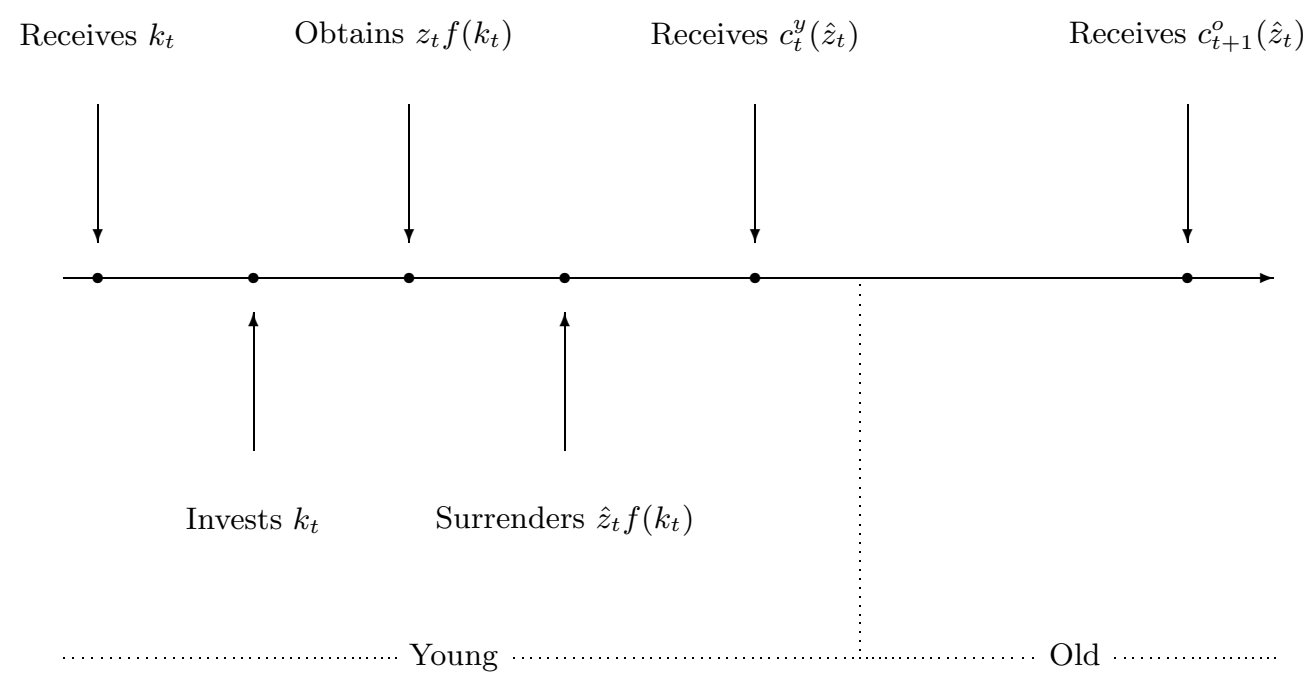

Figure 10: Timing in Planner's Problem.

for optimality. That is, $c_{t}^{y} \equiv c_{h, t}^{y}=c_{l, t}^{y}$ and $c_{t}^{o} \equiv c_{h, t}^{o}=c_{l, t}^{o}$ for every $t$. But this violates (13).

Start with the $\xi=0$ case. In Section 3 we argued that, for $\xi=0$, our model is a simple extension of Diamond's, the only difference being that in our model individuals face idiosyncratic risk. In this case, the planner's solution is to provide full insurance. The presence of idiosyncratic risk becomes immaterial to the determination of the efficient allocation. In fact, the following holds at all times:

$$
u^{\prime}\left(c_{t}^{y}\right)=\beta\left[\bar{z} f^{\prime}\left(k_{t+1}\right)+(1-\delta)\right] u^{\prime}\left(c_{t+1}^{o}\right)
$$

and

$$
u^{\prime}\left(c_{t}^{y}\right)=\frac{\beta}{\gamma} u^{\prime}\left(c_{t}^{o}\right)
$$

The steady state capital stock is then determined by the modified golden rule condition

$$
\bar{z} f^{\prime}(k)=\frac{1}{\gamma}-(1-\delta)
$$

where $\bar{z}=\rho z_{h}+(1-\rho) z_{l}$.

Now consider the more interesting case, $\xi>0$. Let $\lambda_{t}$ and $\mu_{t}$ be the multipliers associated with the constraints (12) and (13), respectively. Then the planner's optimal 
resource allocation satisfies the following conditions:

$$
\begin{array}{r}
\frac{u^{\prime}\left(c_{h, t}^{y}\right)}{u^{\prime}\left(c_{h, t+1}^{o}\right)}=\frac{\beta \lambda_{t}}{\gamma \lambda_{t+1}}, \\
\frac{(1-\rho) u^{\prime}\left(c_{l, t}^{y}\right)-\mu_{t} u^{\prime}\left(c_{l, t}^{y}+\xi \Delta f\left(k_{t}\right)\right)}{\left[(1-\rho)-\mu_{t}\right] u^{\prime}\left(c_{l, t+1}^{o}\right)}=\frac{\beta \lambda_{t}}{\gamma \lambda_{t+1}},
\end{array}
$$

where $\mu_{t}>0$. Given our assumption that $u^{\prime \prime}<0$, it follows that

$$
\frac{u^{\prime}\left(c_{l, t}^{y}\right)}{u^{\prime}\left(c_{l, t+1}^{o}\right)}<\frac{u^{\prime}\left(c_{h, t}^{y}\right)}{u^{\prime}\left(c_{h, t+1}^{o}\right)} .
$$

Condition (14) is the restatement of a general result due to Rogerson (1985). Given the low state, individuals consume too much in the first period of their lives. If they could, they would transfer resources to the second period of their lives.

A further necessary condition for optimality is that

$$
\gamma \frac{\lambda_{t+1}}{\lambda_{t}}\left[\bar{z} f^{\prime}\left(k_{t+1}\right)+1-\delta\right]=1+\gamma \frac{\mu_{t+1}}{\lambda_{t}} \xi \Delta f^{\prime}\left(k_{t+1}\right) u^{\prime}\left(c_{l, t+1}^{y}+\xi \Delta f\left(k_{t+1}\right)\right) .
$$

Since $\mu_{t+1}>0$, it follows that

$$
\gamma \frac{\lambda_{t+1}}{\lambda_{t}}\left[\bar{z} f^{\prime}\left(k_{t+1}\right)+1-\delta\right]>1
$$

This condition implies that the steady state capital stock satisfies

$$
\bar{z} f^{\prime}(k)>\frac{1}{\gamma}-(1-\delta)
$$

Hence, with private information the social planner accumulates less capital than would be accumulated under symmetric information. This result is analogous to the one reached by Khan and Ravikumar (2001); the intuition is the same. When choosing the level of investment, the planner recognizes that a larger capital stock will make the incentive compatibility constraint harder to satisfy for future generations. In other words, a larger capital stock will imply less risk sharing, and thus, lower marginal returns. The optimal response is to choose a lower capital stock than would be chosen if $\xi=0$.

In the basic 2-period OLG model, it is well-known that there exists a simple market mechanism that results in consumption being allocated just as a benevolent planner would allocate it. Does such a mechanism exist in our more general model? For $\xi=0$, it exists, and it is very simple. It involves introducing intermediaries that 
borrow from the old and lend to the young via a contract that offers full insurance to entrepreneurs. When $\xi>0$, the answer is less obvious. It is clear, however, that such a mechanism would have to satisfy condition (14). If individuals can commit to interacting with only one intermediary during their life-times, then it is easy to prove that (14) holds. If individuals cannot commit to exclusive lifetime contracts, then the allocation will satisfy (14) only if financial institutions can perfectly monitor the agents' use of alternative borrowing and lending opportunities. In fact, consider the case studied by Allen (1985), in which individuals can engage in unmonitored intertemporal borrowing and lending at a given rate $r$. After receiving the first-period allocations from their intermediary, individuals will trade until their consumption allocations satisfy

$$
\frac{u^{\prime}\left(c_{l, t}^{y}\right)}{u^{\prime}\left(c_{l, t+1}^{o}\right)}=\frac{u^{\prime}\left(c_{h, t}^{y}\right)}{u^{\prime}\left(c_{h, t+1}^{o}\right)}=\beta(1+r) .
$$

Thus, with unmonitored borrowing and lending, any two-period contract collapses to a sequence of one-period contracts of the type considered in the main body of the paper. ${ }^{37}$

\section{B Derivation of the Optimal Contracting Problem (P2)}

In this section we cast the relationship between lender and entrepreneur as a message game with asymmetric information. Instead of surrendering their output and receiving a transfer in return, entrepreneurs simply pay a contingent return on the capital borrowed. We show that the Constrained-Pareto Optimal Contract in this environment implies the same allocation as the one that solves problem (P2).

Differently from what is standard in the message game literature and similarly to Lacker and Weinberg (1989), we assume that besides sending a message drawn from an arbitrary space $\mathcal{M}$, each entrepreneur takes an action that consists in showing (displaying) his output to his lender. A contract at time $t$ is now given by a scalar $k_{t}$ and by a return function $R_{t}: \mathcal{M} \times\left\{z_{h}, z_{l}\right\} \rightarrow \Re$. The crucial assumption is that hiding, i.e. displaying an amount of output lower than the outcome of production, is costly. $^{38}$

\footnotetext{
${ }^{37}$ A similar point is made in Section 7 of Atkeson and Lucas (1992).

${ }^{38}$ We assume that an entrepreneur cannot display more output than he actually obtained. It is easy to prove that this assumption implies no loss of generality. That is, our results would not change if, consistently with a different notion of display, the entrepreneur could show more output than he has. This would be the case if displaying output meant disclosing balance sheet and/or income statement data.
} 
Borrows $k_{t} \quad$ Obtains $z_{t} f\left(k_{t}\right) \quad$ Pays out $R_{t}\left(\hat{z}_{t}, \tilde{z}_{t}\right) k_{t} \quad$ Lends $s_{t}$

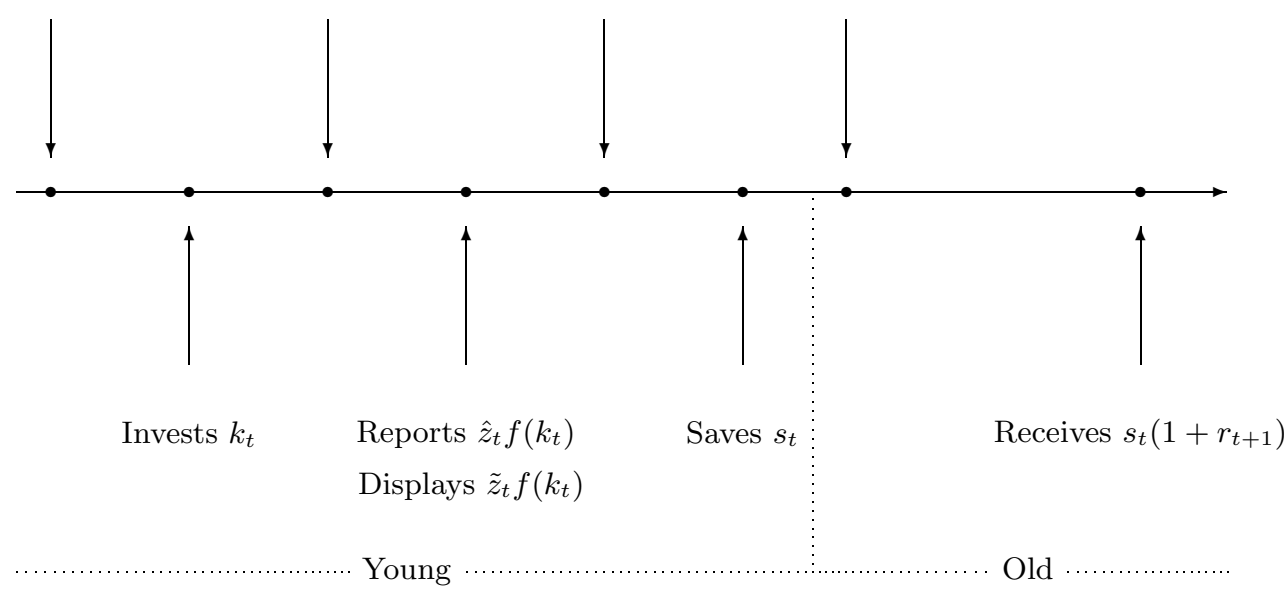

Figure 11: Timing.

By the Revelation Principle, we can restrict our attention to the case in which $\mathcal{M} \equiv\left\{z_{h}, z_{l}\right\}$ and the reports are truthful. However, we do not require the amounts displayed to be consistent with the reports. Figure 11 displays the timing. After having observed his outcome $z_{t} f\left(k_{t}\right)$, the entrepreneur makes a claim about the quality of his project $\hat{z}_{t} \in\left\{z_{h}, z_{l}\right\}$ and displays output in measure $\tilde{z}_{t}$. Feasibility requires that $\tilde{z}_{l}=z_{l}$ and $\tilde{z}_{h} \in\left\{z_{h}, z_{l}\right\}$. Finally, he transfers to the lender an amount $R_{t}(\hat{z}, \tilde{z}) k_{t}$.

A contract at time $t$ is a capital advance $k_{t}$ and a return schedule $R_{t}(\hat{z}, \tilde{z})$ that solve

$$
\begin{gathered}
\max _{k_{t}, \tilde{z} \in\left\{z_{h}, z_{l}\right\}, R_{t}\left(\hat{z}_{h}, \tilde{z}\right)} \rho v\left[z_{h} f\left(k_{t}\right)-R_{t}\left(z_{h}, \tilde{z}\right) k_{t}-(1-\xi)\left(z_{h}-\tilde{z}\right) f\left(k_{t}\right), r_{t+1}\right] \\
+(1-\rho) v\left[z_{l} f\left(k_{t}\right)-R_{t}\left(z_{l}, z_{l}\right) k_{t}, r_{t+1}\right]
\end{gathered}
$$

subject to

$$
\begin{gathered}
\rho R_{t}\left(z_{h}, \tilde{z}_{h}\right)+(1-\rho) R_{t}\left(z_{l}, z_{l}\right)=r_{t}+\delta \\
\left(z_{h}, \tilde{z}_{h}\right)=\arg \max _{\hat{z}, \tilde{z} \in\left\{z_{h}, z_{l}\right\}} v\left[z_{h} f\left(k_{t}\right)-R_{t}(\hat{z}, \tilde{z}) k_{t}-(1-\xi)\left(z_{h}-\tilde{z}\right) f\left(k_{t}\right), r_{t+1}\right] \\
v\left[z_{l} f\left(k_{t}\right)-R_{t}\left(z_{l}, z_{l}\right) k_{t}\right] \geq v\left[z_{l} f\left(k_{t}\right)-R_{t}\left(z_{h}, z_{l}\right) k_{t}\right]
\end{gathered}
$$

The deadweight loss associated with hiding cash flows in the high state is $(1-\xi) \Delta f\left(k_{t}\right)$, i.e. a fraction $(1-\xi)$ of the output hidden. Condition (15) requires truthful reporting and optimal display of output by high-outcome entrepreneurs. Condition (16) requires truthful reporting by low-outcome entrepreneurs. Following an argument made by Lacker and Weinberg (1989), Lemma 2 shows that optimal return schedules are independent of the report $\hat{z}$. 
Lemma 2 For all $\tilde{z} \in\left\{z_{h}, z_{l}\right\}, R_{t}\left(z_{h}, \tilde{z}\right)=R_{t}\left(z_{l}, \tilde{z}\right)$ without loss of generality.

Proof. We first show that $R_{t}\left(z_{h}, z_{l}\right)=R_{t}\left(z_{l}, z_{l}\right)$. Condition (16) implies that $R_{t}\left(z_{h}, z_{l}\right) \geq R_{t}\left(z_{l}, z_{l}\right)$. If $\tilde{z}_{h}=z_{l}$, then (16) implies that $-R_{t}\left(z_{h}, z_{l}\right)-(1-\xi) \Delta f\left(k_{t}\right) \geq$ $-R_{t}\left(z_{l}, z_{l}\right)-(1-\xi) \Delta f\left(k_{t}\right)$. In turn, this implies $R_{t}\left(z_{h}, z_{l}\right) \leq R_{t}\left(z_{l}, z_{l}\right)$. Otherwise, if $\tilde{z}_{h}=z_{h}$, then $-R_{t}\left(z_{h}, z_{h}\right) \geq-R_{t}\left(z_{h}, z_{l}\right)-(1-\xi) \Delta f\left(k_{t}\right)$. Therefore there is no loss in generality in imposing $R_{t}\left(z_{h}, z_{l}\right)=R_{t}\left(z_{l}, z_{l}\right)$.

We now show that $R_{t}\left(z_{h}, z_{h}\right)=R_{t}\left(z_{l}, z_{h}\right)$. If $\tilde{z}_{h}=z_{h}$, then (15) implies that $R_{t}\left(z_{l}, z_{h}\right) \geq R_{t}\left(z_{h}, z_{h}\right)$. Otherwise, if $\tilde{z}_{h}=z_{l}$, then (15) implies $-R_{t}\left(z_{h}, z_{l}\right)-(1-$ $\xi) \Delta \geq-R_{t}\left(z_{h}, z_{h}\right)$. In either case, there is no loss in generality in imposing that $R_{t}\left(z_{l}, z_{h}\right)=R_{t}\left(z_{h}, z_{h}\right)$.

In light of Lemma 2, we can rewrite the optimal contracting problems as

$$
\begin{aligned}
\max _{k_{t}, \tilde{z} \in\left\{z_{h}, z_{l}\right\}, R_{t}(\tilde{z})} \rho v\left[z_{h} f\left(k_{t}\right)-R_{t}(\tilde{z}) k_{t}-(1-\xi)\left(z_{h}-\tilde{z}\right) f\left(k_{t}\right), r_{t+1}\right] \\
+(1-\rho) v\left[z_{l} f\left(k_{t}\right)-R_{t}\left(z_{l}\right) k_{t}, r_{t+1}\right]
\end{aligned}
$$

subject to

$$
\begin{gathered}
\rho R_{t}\left(\tilde{z}_{h}\right)+(1-\rho) R_{t}\left(z_{l}\right)=r_{t}+\delta \\
\tilde{z}_{h}=\arg \max _{\tilde{z} \in\left\{z_{h}, z_{l}\right\}} v\left[z_{h} f\left(k_{t}\right)-R_{t}(\tilde{z}) k_{t}-(1-\xi)\left(z_{h}-\tilde{z}\right) f\left(k_{t}\right), r_{t+1}\right]
\end{gathered}
$$

Lemma 3 shows that no Constrained-Pareto optimal contracts involve hiding.

Lemma 3 Hiding is never optimal, i.e. $\tilde{z}_{h}=z_{h}$.

Proof. By contradiction, assume that the optimal contract $\left\{k_{t}, R_{t}(\cdot)\right\}$ implies $\tilde{z}_{h}=z_{l}$. Consider the return schedule $R_{t}^{\prime}$ such that $R_{t}^{\prime}\left(z_{h}\right)=R_{t}^{\prime}\left(z_{l}\right)=R_{t}\left(z_{l}\right)$. The contract $\left\{k_{t}, R_{t}^{\prime}(\cdot)\right\}$ implies $\tilde{z}_{h}=z_{h}$, satisfies (17), and provides the entrepreneur with a strictly greater utility. This contradicts the initial assumption.

The intuition for this result is simple. The spread between the incomes of highand low-outcome entrepreneurs is invariant to the level of output displayed $\tilde{z} f\left(k_{t}\right)$. In any contract that prescribes hiding, the income of high-outcome entrepreneurs is given by $z_{h} f\left(k_{t}\right)-R_{t}\left(z_{l}\right) k_{t}-(1-\xi) \Delta f\left(k_{t}\right)$. Therefore $m_{t}\left(z_{h}\right)-m_{t}\left(z_{l}\right)=\xi \Delta f\left(k_{t}\right)$. Since $v\left(\cdot ; r_{t}\right)$ is strictly increasing and strictly concave, any optimal contract with no hiding will require $R_{t}\left(z_{h}\right)=R_{t}\left(z_{l}\right)-(1-\xi) \Delta f\left(k_{t}\right)$. Thus, also in this case, 
$m_{t}\left(z_{h}\right)-m_{t}\left(z_{l}\right)=\xi \Delta f\left(k_{t}\right)$. In the case of no hiding however, the total surplus is larger, as there is no deadweight loss. ${ }^{39}$ Lemma 3 also holds in the case in which a portion of $(1-\xi) \Delta f\left(k_{t}\right)$ accrues to the intermediary. In the extreme case in which there is no deadweight loss, optimal contracts with hiding and no hiding imply the same allocation. ${ }^{40}$

By Lemma 3 we can now restate the optimal contracting problems as follows:

$$
\max _{k_{t}, R_{t}\left(z_{h}\right), R_{t}\left(z_{l}\right)} \rho v\left[z_{h} f\left(k_{t}\right)-R_{t}\left(z_{h}\right) k_{t}, r_{t+1}\right]+(1-\rho) v\left[z_{l} f\left(k_{t}\right)-R_{t}\left(z_{l}\right) k_{t}, r_{t+1}\right]
$$

subject to

$$
\begin{gathered}
\rho R_{t}\left(z_{h}\right)+(1-\rho) R_{t}\left(z_{l}\right)=r_{t}+\delta \\
v\left[z_{h} f\left(k_{t}\right)-R_{t}\left(z_{h}\right) k_{t}, r_{t+1}\right] \geq v\left[z_{h} f\left(k_{t}\right)-R_{t}\left(z_{l}\right) k_{t}-(1-\xi) \Delta f\left(k_{t}\right), r_{t+1}\right]
\end{gathered}
$$

It is now evident that for any contract $\left\{k_{t}, R_{t}\left(z_{h}\right), R_{t}\left(z_{l}\right)\right\}$ that solves problem (P3), there is a contract $\left\{k_{t}, \tau_{t}\left(z_{h}\right), \tau_{t}\left(z_{l}\right)\right\}$ with

$$
\tau\left(z_{i}\right) \equiv z_{i} f\left(k_{t}\right)-R_{t}\left(z_{i}\right) k_{t} \quad \text { for } i=h, l
$$

that solves Problem (P2) and implies the same levels of income $m_{t}\left(z_{h}\right)$ and $m_{t}\left(z_{l}\right)$.

\section{Occupational choice}

In this section we extend our model by endogeneizing the fraction of individuals that become entrepreneurs. With this extension a larger value of $\xi$ (i.e. a worse risk sharing technology) can be accommodated along two margins: prices (as above) and quantities. That is, greater $\xi$ can result in a greater fraction young agents choosing entrepreneurship, with each being advanced less capital. Our principal objective is to determine whether and how this new adjustment margin alters our main result from Section 3.

We assume that the production function is of the form $z f(k, n)$, where $n$ denotes labor input. We assume that $f$ is homogeneous of degree $\lambda<1$, so that output is not exhausted if capital and labor are paid their marginal products, which occurs when $\xi=0$. We assume that each individual is endowed with a unit of time available

\footnotetext{
${ }^{39}$ Lacker and Weinberg (1989) also note that when the hiding cost function is linear, then contracts with no hiding are always optimal. However, the same authors show the existence of alternative specifications of the cost function for which Lemma 3 does not hold.

${ }^{40}$ The proof of this statement is available from the authors upon request. It was not included because it requires working with a continuum of outcomes. In fact with a discrete set of outcomes, any hiding would be detected by the lender.
} 


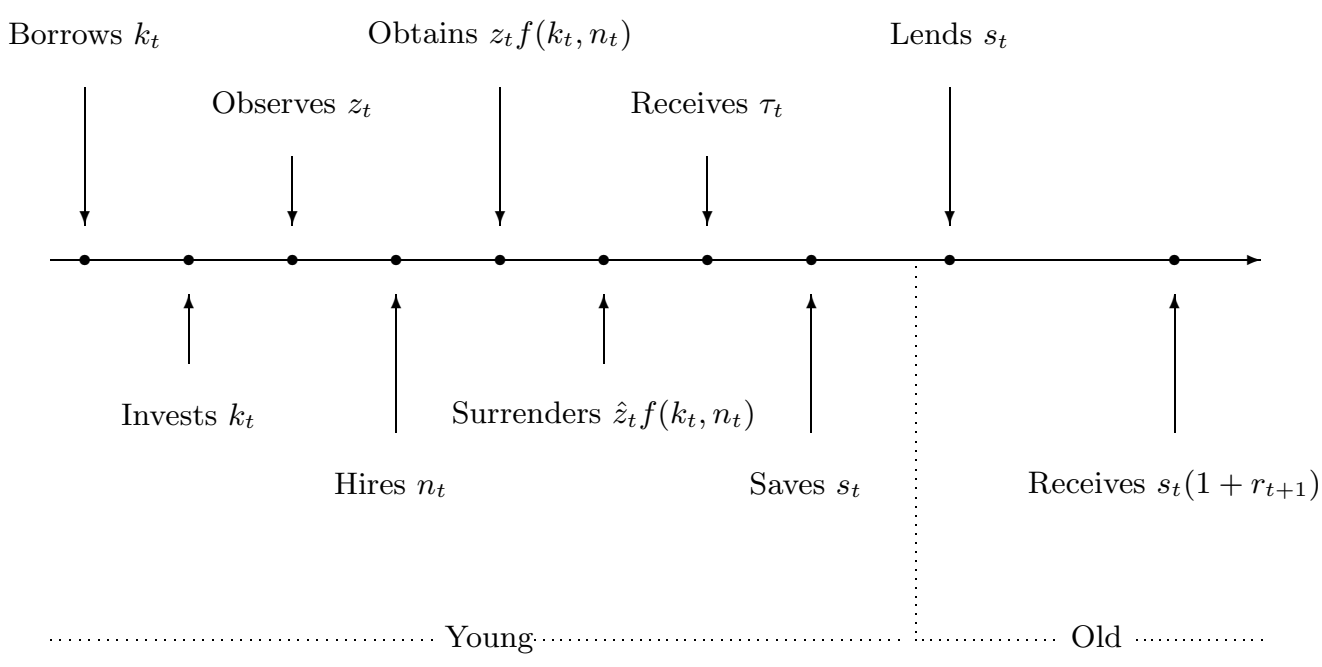

Figure 12: Timing in the Model with Occupational Choice.

for work (i.e., we ignore the work/leisure choice) and decides how to allocate it, either becoming an entrepreneur who hires labor, or working for a wage. Thus, in equilibrium, every cohort will be divided into workers and entrepreneurs.

We assume that labor is freely mobile, so that at a single wage rate $w_{t}$ must prevail in equilibrium. The lifetime utility of a worker is given by $v\left(w_{t} ; r_{t+1}\right)$, where the indirect utility function $v$ is defined by $(\mathrm{P} 1)$.

The entrepreneurs expected lifetime utility is

$$
V\left(\tau_{h t}, \tau_{l t} ; r_{t+1}\right) \equiv \rho v\left(\tau_{h t} ; r_{t+1}\right)+(1-\rho) v\left(\tau_{l t} ; r_{t+1}\right)
$$

where $v$ is defined as in $(\mathrm{P} 1)$.

Figure 12 describes the timing of an entrepreneur's choices. Whereas capital is put in place at the beginning of the period (i.e. before the value of the variable $z$ is observed), workers can be hired after $z$ is observed.

A contract is, as above, a capital advance, $k_{t}$, and contingent transfers $\tau_{i t}, i=$ $h, l$. But, different from above, the contract now includes hiring recommendations, $n_{i t}, i=h, l$. We assume that the employment level chosen by the entrepreneur is public information. Thus, if an entrepreneur misreports his production quality, he must hire the amount of labor that is consistent with his report. Optimal contracts solve:

$$
\max _{k_{t}, n_{h t}, n_{l t}, \tau_{h t}, \tau_{l t}} V\left(\tau_{h t}, \tau_{l t} ; r_{t+1}\right),
$$

subject to

$$
v\left(\tau_{h t} ; r_{t+1}\right) \geq v\left[\tau_{l t}+\xi \Delta f\left(k_{t}, n_{l t}\right) ; r_{t+1}\right],
$$




$$
\begin{gathered}
\bar{\tau}_{t} \equiv \rho \tau_{h t}+(1-\rho) \tau_{l t}=\rho\left[z_{h} f\left(k_{t}, n_{h t}\right)-w_{t} n_{h t}\right]+ \\
(1-\rho)\left[z_{l} f\left(k_{t}, n_{l t}\right)-w_{t} n_{l t}\right]-\left(r_{t}+\delta\right) k_{t}, \\
z_{i} f_{2}\left(k_{t}, n_{i t}\right)=w_{t} \quad \text { for } i=h, l .
\end{gathered}
$$

Condition (23) requires that hiring be efficient. Absent this assumption, it could be optimal for the intermediary to recommend hiring labor $n_{l t}$ that is lower than what is ex-post efficient because this would relax the incentive compatibility constraint and allow better risk sharing (i.e. lower spread $\tau_{h t}-\tau_{l t}$ ). In other words, the labor hiring decision would help in providing incentives. Since our intent is to determine how endogeneizing the number of entrepreneurs influences our results, and not to determine the impact of changes in the contracting environment, we require intermediaries not to recommend inefficient hiring.

It is immediate that (21) binds. Then, by strict monotonicity of $v$, we also have

$$
\tau_{h t}=\tau_{l t}+\xi \Delta f\left(k_{t}, n_{l t}\right) .
$$

Definition 4 Given an initial aggregate capital stock $K_{0}>0$, a competitive equilibrium consists of the consumption level of the initial old, $c_{0}^{o}$, contingent consumption allocations for young and old entrepreneurs, $\left\{c_{h t}^{y}, c_{l t}^{y}\right\}_{t=0}^{\infty}$ and $\left\{c_{h t}^{o}, c_{l t}^{o}\right\}_{t=1}^{\infty}$, consumption allocations for workers, $\left\{c_{w t}^{y}, c_{w t+1}^{o}\right\}_{t=0}^{\infty}$, and sequences of prices, $\left\{r_{t}, w_{t}\right\}_{t=0}^{\infty}$, aggregate labor force, $\left\{N_{t}\right\}_{t=0}^{\infty}$, aggregate capital $\left\{K_{t}\right\}_{t=0}^{\infty}$, contracts $\left\{k_{t}, \tau_{h t}, \tau_{l t}\right\}_{t=0}^{\infty}$, and individual employment levels $\left\{n_{h t}, n_{l t}\right\}_{t=0}^{\infty}$ such that for all $t \geq 0$

1. consumers optimize, i.e. $c_{0}^{o}=k_{0}\left(1+r_{0}\right)$; for $i=h, l c_{i t}^{y}=\tau_{i t}-s\left(\tau_{i t}, r_{t+1}\right)$ and $c_{i t+1}^{o}=s\left(\tau_{i t}, r_{t+1}\right)\left(1+r_{t+1}\right) ; c_{w t}^{y}=w_{t}-s\left(w_{t}, r_{t+1}\right) ;$ and $c_{w t+1}^{o}=s\left(w_{t}, r_{t+1}\right)(1+$ $\left.r_{t+1}\right)$;

2. contracts and individual employment levels are optimal, i.e. $\left(k_{t}, \tau_{h t}, \tau_{l t}, n_{h t}, n_{l t}\right)$ solves problem (P2),

3. ex-ante, young agents are indifferent between occupations:

$$
v\left(w_{t} ; r_{t+1}\right)=V\left(\tau_{h t}, \tau_{l t} ; r_{t+1}\right)
$$

4. the labor market clears:

$$
N_{t}=\left(1-N_{t}\right)\left[\rho n_{h t}+(1-\rho) n_{l t}\right]
$$


5. the aggregate capital stock equals capital demand:

$$
K_{t}=\left(1-N_{t}\right) k_{t}
$$

and

6. the aggregate capital stock equals capital supply:

$$
K_{t+1}=N_{t} s\left(w_{t} ; r_{t+1}\right)+\left(1-N_{t}\right)\left[\rho s\left(\tau_{h t} ; r_{t+1}\right)+(1-\rho) s\left(\tau_{l t} ; r_{t+1}\right)\right] .
$$

Using (22) and (24), (P2) can be approached in the same way as we analyzed the simpler problem in the body of the paper. The tangency condition

$$
\left.\frac{\partial \bar{\tau}_{t}}{\partial k_{t}}\right|_{B C}=\left.\frac{\partial \bar{\tau}_{t}}{\partial k_{t}}\right|_{V} .
$$

is necessary for optimality, where

$$
\begin{gathered}
\left.\frac{\partial \bar{\tau}_{t}}{\partial k_{t}}\right|_{B C}=\rho z_{h} f_{1}\left(k_{t}, n_{h t}\right)+(1-\rho) z_{l} f_{1}\left(k_{t}, n_{l t}\right)-\left(r_{t}+\delta\right), \\
\left.\frac{\partial \bar{\tau}_{t}}{\partial k_{t}}\right|_{V}=-\rho(1-\rho) \xi \Delta\left[f_{1}\left(k_{t}, n_{l t}\right)-f_{2}\left(k_{t}, n_{l t}\right) \frac{f_{21}\left(k_{t}, n_{l t}\right)}{f_{22}\left(k_{t}, n_{l t}\right)}\right] \frac{u^{\prime}\left(c_{h t}\right)-u^{\prime}\left(c_{l t}\right)}{\rho u^{\prime}\left(c_{h t}\right)+(1-\rho) u^{\prime}\left(c_{l t}\right)} .
\end{gathered}
$$

Along with the budget constraint, the tangency condition defines the optimal capital advance at $t$. Also, it is easy to verify that condition (25) reduces to

$$
u\left(w_{t}\right)=\rho u\left(\tau_{h t}\right)+(1-\rho) u\left(\tau_{l t}\right)
$$

and is so independent from $r_{t+1}$.

To make progress, assume a Cobb-Douglas technology: $f\left(k_{t}, n\right)=k_{t}^{\alpha} n_{t}^{\gamma}$ with $\alpha \geq 0, \gamma \geq 0$ and $\alpha+\gamma<1$. In this case, transfers are linear in production. It will follow that the fraction of entrepreneurs is constant both in a steady state and along the transition path.

Proposition 4 If the technology is Cobb-Douglas then $N_{t}=N$ for all $t$.

Proof. We start by showing that transfers are linear in production. Observe first that (23) and (26) imply

$$
n_{i t}=A_{i} \frac{N_{t}}{1-N_{t}} \quad \text { for } i=h, l
$$

where

$$
\begin{aligned}
A_{h} & \equiv\left[\rho+(1-\rho)\left(\frac{z_{l}}{z_{h}}\right)^{1 /(1-\gamma)}\right]^{-1} \\
A_{l} & \equiv\left(\frac{z_{l}}{z_{h}}\right)^{1 /(1-\gamma)} A_{h} .
\end{aligned}
$$


Suppose

$$
\tau_{i t}=g_{i} \tilde{y}_{t} \quad \text { for } i=h, l
$$

where

$$
\tilde{y}_{t} \equiv k_{t}^{\alpha}\left(\frac{N_{t}}{1-N_{t}}\right)^{\gamma}
$$

for constants $g_{i}, i=h, l$. We verify the optimality of (29). Assuming (29),

$$
\omega \equiv \frac{u^{\prime}\left(c_{h t}\right)-u^{\prime}\left(c_{l t}\right)}{\rho u^{\prime}\left(c_{h t}\right)+(1-\rho) u^{\prime}\left(c_{l t}\right)}=\frac{u^{\prime}\left(g_{h}\right)-u^{\prime}\left(g_{l}\right)}{\rho u^{\prime}\left(g_{h}\right)+(1-\rho) u^{\prime}\left(g_{l}\right)} ;
$$

where the right hand side is constant over time. The optimal contract is then completely described by (27), where

$$
\begin{aligned}
\left.\frac{\partial \bar{\tau}_{t}}{\partial k_{t}}\right|_{B C} & =\alpha\left[\rho z_{h} A_{h}^{\gamma}+(1-\rho) z_{l} A_{l}^{\gamma}\right] \frac{\tilde{y}_{t}}{k_{t}}-\left(r_{t}+\delta\right) \\
\left.\frac{\partial \bar{\tau}_{t}}{\partial k_{t}}\right|_{V} & =-\rho(1-\rho) \xi \Delta \omega \frac{\alpha}{1-\gamma} A_{l}^{\gamma} \frac{\tilde{y}_{t}}{k_{t}},
\end{aligned}
$$

the zero-profit condition

$$
\bar{\tau}_{t}=(1-\gamma)\left[\rho z_{h} A_{h}^{\gamma}+(1-\rho) z_{l} A_{l}^{\gamma}\right] \tilde{y}_{t}-\left(r_{t}+\delta\right) k_{t},
$$

and the definitions of transfers

$$
\begin{aligned}
g_{h} \tilde{y}_{t} & =\bar{\tau}_{t}+(1-\rho) \Delta \xi A_{l}^{\gamma} \tilde{y}_{t} \\
g_{l} \tilde{y}_{t} & =\bar{\tau}_{t}-\rho \Delta \xi A_{l}^{\gamma} \tilde{y}_{t} .
\end{aligned}
$$

Substituting the preceding four equalities into (30) and (31) leaves $g_{h}$ and $g_{l}$ as a function of parameters only, verifying our conjecture. Rewriting problem (P4) in the same way we rewrote problem (P1) in Section 3.2, one can show that (P4) admits a unique solution. Therefore transfers must take the form described by (29).

Since wages can be written

$$
w_{t}=\gamma z_{l} A_{l}^{\gamma-1} \tilde{y}_{t} \frac{1-N_{t}}{N_{t}},
$$

the result that $N_{t}=N$ follows from (28) and (29).

Proposition 4 allows us to recast the whole problem as if capital were the only input to production, viz. the production function may be rewritten as

$$
y_{t}=\tilde{z}_{t} B k_{t}^{\alpha},
$$

where project quality is the product of a stochastic component $\tilde{z}_{t} \in\left\{\tilde{z}_{l}, \tilde{z}_{h}\right\}$ and a deterministic component $B$. Both newly defined parameters, $\tilde{z}_{t}$ and $B$, are complicated functions of the remaining parameters of the model. However, only $B$ depends on $\xi$. 
This finding implies that, qualitatively, the dynamics implied by the extended model are the same as in the simpler one. But more specifically, changes in $\xi$ lead not only to effects on the aggregate demand and supply of capital analogous to those described in Section 3, and also to new effects operating through $B$. The variation in $B$ triggered by the change in $\xi$ captures precisely the adjustment along the entrepreneurial sector margin that we wish to emphasize.

The expression for aggregate employment turns out to be

$$
N=\frac{\gamma z_{l} A_{l}^{\gamma-1}}{\gamma z_{l} A_{l}^{\gamma-1}+\left[\rho g_{h}^{1-\sigma}+(1-\rho) g_{l}^{1-\sigma}\right]^{1 /(1-\sigma)}},
$$

and

$$
B=\left(\frac{\gamma z_{l} A_{l}^{\gamma-1}}{\rho g_{h}^{1-\sigma}+(1-\rho) g_{l}^{1-\sigma}}\right)^{\gamma},
$$

where the parameters $A_{l}, g_{h}$ and $g_{l}$ are defined in the proof of Proposition 4.

Like Figure 6, Figure 13 shows the time paths of several variables for two economies that differ only in the levels of investor protection. For the chosen parameters, the fraction of entrepreneurs $\left(1-N_{t}\right)$ is larger in the economy with poorer protection. A given aggregate capital may now be split across a larger number of entrepreneurs, reducing the capital advanced to each, and so offsetting the increase in risk and expected transfer $\bar{\tau}$ triggered by an increase in $\xi$. This dampens the surge in savings.

In summary, the qualitative effects of poorer protection on the paths of interest rate, aggregate capital, and transfers, resemble those in Section 3. Despite the introduction of a new margin for adjustment, an increase in $\xi$ still has a positive effect on capital accumulation.

\section{References}

Aiyagari, R. (1994). Uninsured idiosyncratic risk and aggregate saving. Quarterly Journal of Economics 109, 659-84.

Alesina, A., V. Grilli, and G. M. Milesi-Ferretti (1994). The political economy of capital controls. In L. Leiderman and A. Razin (Eds.), Capital Mobility: The impact on Consumption, Investment, and Growth, pp. 289-321. Cambridge University Press.

Allen, F. (1985). Repeated principal-agent relationships with lending and borrowing. Economics Letters 17, 27-31. 

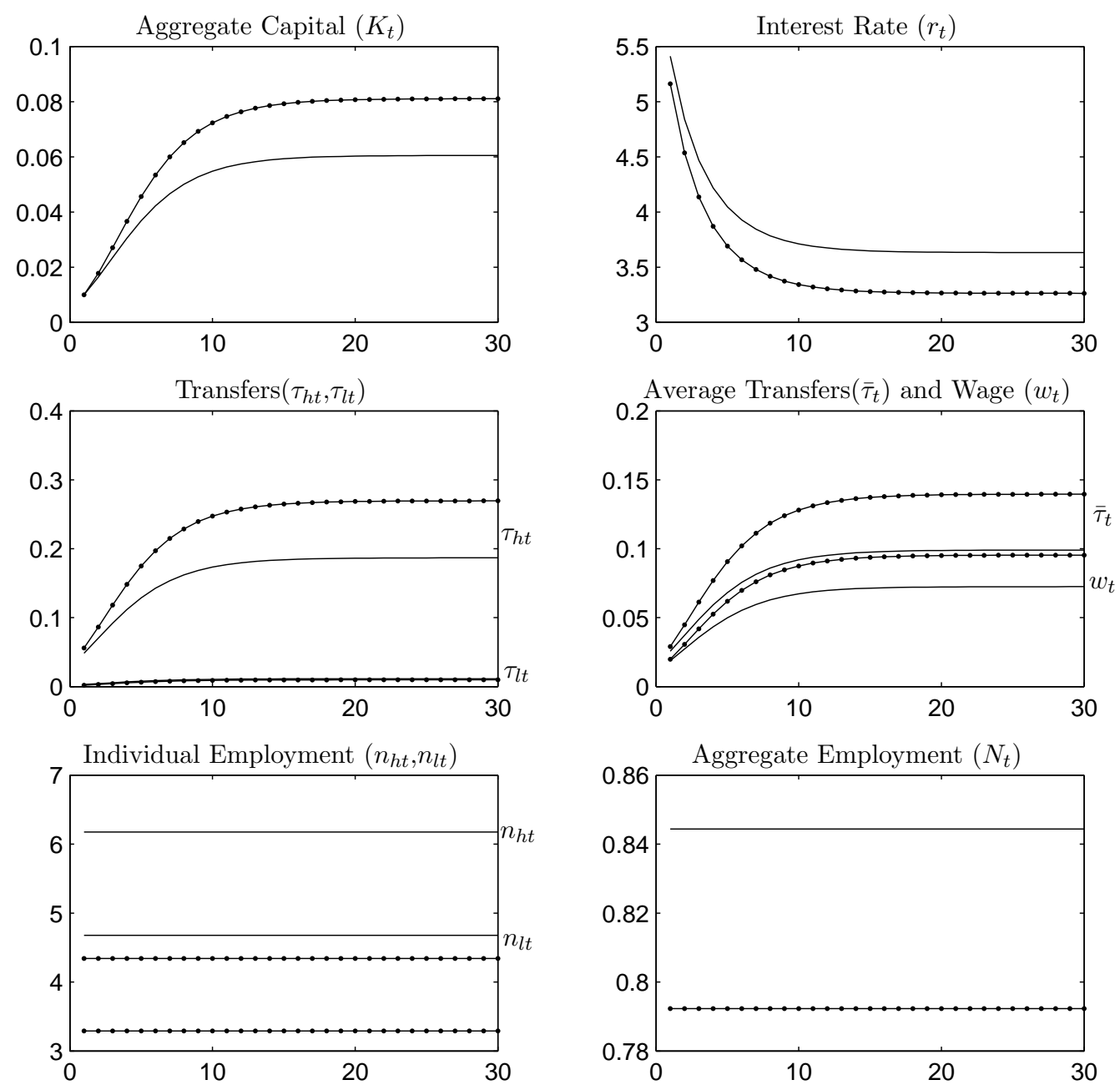

Figure 13: Comparative Dynamics (Dotted line $=$ higher $\xi$ ).

Almeida, H. and D. Wolfenzon (2002). The effect of external finance and internal capital markets on the equilibrium allocation of capital. New York University.

Arteta, C., B. Eichengreen, and C. Wyplosz (2001). When does capital account liberalization help more than it hurts? NBER Working Paper \#8414.

Atkeson, A. and R. Lucas (1992). On efficient distribution with private information. Review of Economic Studies 59, 427-53.

Barro, R. and J.-W. Lee (1996). International measures of schooling years and schooling quality. American Economic Review Papers and Proceedings 86, 218-23.

Beck, T., R. Levine, and N. Loayza (2000a). Finance and the sources of growth. Journal of Financial Economics 58, 261-300. 
Beck, T., R. Levine, and N. Loayza (2000b). Financial intermediation and growth: Causality and causes. Journal of Monetary Economics 46, 31-77.

Bencivenga, V. and B. Smith (1991). Financial intermediation and endogenous growth. Review of Economic Studies 58, 195-209.

Bertrand, M., P. Mehta, and S. Mullainathan (2002). Ferreting out tunneling: An application to Indian business groups. Quarterly Journal of Economics 117, 121148.

Carroll, C. D., B.-K. Rhee, and C. Rhee (1994). Are there cultural effects on saving? Some cross-sectional evidence. Quarterly Journal of Economics 109, 685-99.

Chinn, M. D. and H. Ito (2002). Capital account liberalization, institutions, and financial development: Cross country evidence. University of Wisconsin at Madison.

Cho, Y. C. and D. Vittas (1995). Credit policies. Lessons from East Asia. Policy Research Working Paper \# 1458 - The World Bank.

Claessens, S., S. Djankov, and L. C. Xu (2000). Corporate performance in the East Asian financial crisis. The World Bank Research Observer 15, 23-46.

Demirgüç, A. and V. Maksimovic (1998). Law, finance, and firm growth. Journal of Finance 54, 2107-2137.

Devereux, M. and G. Smith (1994). International risk sharing and economic growth. International Economic Review 35, 535-50.

Diamond, P. (1965). National debt in a neoclassical growth model. American Economic Review 55, 1126-50.

Dornbush, R. and Y. C. Park (1987). Korea's growth policy. Brookings Papers on Economic Activity 2, 389-444.

Gentry, W. and G. Hubbard (2000). Entrepreneurship and household saving. NBER Working Paper \#7894.

Goswami, O. (2002). Corporate governance in India. In Taking action against corruption in Asia and the Pacific. Manila: Asian Development Bank Conference Papers and Proceedings. 
Greenwood, J. and B. Jovanovic (1990). Financial development, growth, and the distribution of income. Journal of Political Economy 98, 1076-1107.

Heston, A., L. Summers, and B. Aten (2002). Penn World Table Version 6.1. Philadelphia, PA: Center for International Comparisons at the University of Pennsylvania (CICUP).

Himmelberg, C. P., G. R. Hubbard, and I. Love (2002). Investor protection, ownership, and the cost of capital. Columbia University.

Himmelberg, C. P. and V. Quadrini (2002). Optimal financial contracts and the dynamics of insider ownership. New York University.

Hsieh, C.-T. (2002). What explains the industrial revolution in East Asia? Evidence from the factor markets. American Economic Review 92, 502-26.

Kaminsky, G. L. and S. L. Schmukler (2003). Short-run pain, long-run gain: The effects of financial liberalization. IMF Working Paper 0334.

Khan, A. and B. Ravikumar (2001). Growth and risk-sharing with private information. Journal of Monetary Economics 47, 499-521.

King, R. and R. Levine (1993a). Finance and growth: Schumpeter might be right. Quarterly Journal of Economics 108, 717-37.

King, R. and R. Levine (1993b). Finance, entrepreneurship, and growth. Journal of Monetary Economics 32, 513-42.

La Porta, R., F. Lopez-de Silanes, A. Shleifer, and R. Vishny (1997). Legal determinants of external finance. Journal of Finance 52, 1131-50.

La Porta, R., F. Lopez-de Silanes, A. Shleifer, and R. Vishny (1998). Law and finance. Journal of Political Economy 106, 1113-55.

Lacker, J., R. Levy, and J. Weinberg (1990). Incentive compatible financial contracts, asset prices, and the value of control. Journal of Financial Intermediation 1, 31-56.

Lacker, J. and J. Weinberg (1989). Optimal contracts under costly state falsification. Journal of Political Economy 97, 1345-63.

Levine, R. and S. Zervos (1998). Stock markets, banks and economic growth. American Economic Review 88, 537-558. 
Lewis, K. (1996). What can explain the apparent lack of international consumption risk sharing? Journal of Political Economy 104, 267-97.

Maddison, A. (2001). The World Economy: A millennial perspective. Washington, DC: OECD.

Mankiw, G., D. Romer, and D. Weil (1992). A contribution to the empirics of economic growth. Quarterly Journal of Economics 107, 407-37.

Marcet, A. and R. Marimon (1992). Communication, commitment, and growth. Journal of Economic Theory 58, 219-49.

Nam, I. C., J.-K. Kim, Y. Kang, S. W. Joh, and J.-I. Kim (2001). Corporate governance in Korea. In Corporate Governance in Asia: A comparative perspective. OECD.

Quinn, D. (1997). The correlates of change in international financial regulation. American Political Science Review 91, 531-51.

Rajan, R. G. and L. Zingales (1998). Financial dependence and growth. American Economic Review 88, 559-586.

Rogerson, W. (1985). Repeated moral hazard. Econometrica 53, 69-76.

Shleifer, A. and D. Wolfenzon (2002). Investor protection and equity markets. Journal of Financial Economics 66, 3-27.

Young, A. (1995). The tyranny of numbers: Confronting the statistical realities of the East Asian growth experience. Quarterly Journal of Economics 110, 641-80. 